\title{
Regulatory Redistribution in the Market for Health Insurance
}

\author{
Jeffrey Clemens*
}

September 5, 2012

\begin{abstract}
In the early 1990s, several U.S. states enacted community rating regulations to equalize the private health insurance premiums paid by the healthy and the sick. Consistent with severe adverse selection pressures, I find that their private coverage rates fell by 8-11 percentage points more than rates in comparable markets over subsequent years. By the early 2000s, however, much of these losses had been recovered. The recoveries were coincident with substantial public insurance expansions (for unhealthy adults, pregnant women, and children) and were largest in the markets where public coverage of unhealthy adults expanded most. The analysis highlights an important linkage between the incidence of public insurance programs and redistributive regulations. When targeted at the sick, public insurance expansions can relieve the distortions associated with premium regulations, potentially crowding in private coverage. Such expansions will look particularly attractive to participants in community-rated insurance markets when a federal government shares in the cost of local public insurance programs.
\end{abstract}

\footnotetext{
*Address: Stanford Institute for Economic Policy Research, John A. and Cynthia Fry Gunn Building, Office 235, 366 Galvez Street, Stanford, CA 94305, USA. Telephone: 1-509-570-2690. E-mail: clemens.jeffrey@gmail.com. I am grateful to Kate Baicker, Raj Chetty, Martin Feldstein, Alex Gelber, Ed Glaeser, Joshua Gottlieb, Bruce Meyer, Emily Oster, Kelly Shue, Monica Singhal, Stan Veuger, and participants in seminars at CBO, Harvard, Purdue, the Stanford Institute for Economic Policy Research, UC San Diego, UCLA's School of Public Affairs, the University of Maryland, and the US Naval Postgraduate School for comments and discussions which have moved this project forward. I owe a special thanks to David Cutler and Larry Katz for their comments, advice, and guidance throughout this project. I acknowledge financial support from the Institute for Humane Studies, the Rumsfeld Foundation, and the Taubman Center for the Study of State and Local Governments during the writing of this paper.
} 
In many important markets, regulations play redistributive roles more commonly associated with tax-financed transfer programs. Prominent examples include use of the minimum wage and rent control to increase earnings or reduce prices for those with low incomes. This paper focuses on the use of premium regulations to reduce the cost of insurance for the sick.

The potential for regulations to serve tax-like functions has long been appreciated (Posner, 1971), as has their capacity to generate social insurance transfers (Lee and Saez, 2008; Glaeser and Scheinkman, 1998; Finkelstein, Poterba, and Rothschild, 2009; Lindbeck, 1985). Past work typically analyzes these regulatory policies in isolation, saying little about how they interact with their tax-financed counterparts. ${ }^{1}$ Yet regulatory and tax-financed transfer efforts are almost invariably used in concert. ${ }^{2}$ The Patient Protection and Affordable Care Act (PPACA) illustrates the point, as it simultaneously expands the use of redistributive regulations, insurance purchase subsidies, and public insurance through Medicaid. ${ }^{3}$

This paper analyzes the relationship between Medicaid expansions and regulations known as community rating and guaranteed issue rules. By preventing insurance companies from denying coverage (guaranteed issue) or charging differential premiums (community rating) on the basis of pre-existing conditions, these regulations generate within-market transfers from the healthy to the sick. They may also lead to adverse selection, since the healthy can escape these transfers by reducing or dropping their coverage (Rothschild and Stiglitz, 1976; Buchmueller and DiNardo, 2002).

\footnotetext{
${ }^{1}$ The prior literature on premium regulations, for example, makes scant mention of public insurance programs. A joint analysis of the minimum wage and wage subsidy policies by Lee and Saez (2008) is a notable exception.

${ }^{2}$ Labor market interventions include the minimum wage, wage subsidies, and direct public employment, for example, while housing market interventions include rent control, rental subsidies and public housing projects.

${ }^{3}$ Fine legal lines between the regulatory and tax powers of the federal government ultimately proved pivotal in determining the PPACA's constitutionality.
} 
In a straightforward incidence framework, I show in Section 1 that community rating has two novel implications for Medicaid expansions. The first implication relates to the effect of Medicaid expansions on private market coverage. When Medicaid expansions target those with high health costs, they can relieve adverse selection pressures. ${ }^{4}$ This reduction in community rating's distortions drives the possibility that, when targeted at the sick, Medicaid expansions can crowd in private coverage. This contrasts with the usual expectation that public coverage will partially crowd private coverage out (Cutler and Gruber, 1996). 5

The second implication is that, when the federal government shares in Medicaid's cost, a targeted Medicaid expansion can increase the welfare of private insurance purchasers. With sufficiently generous cost sharing, private insurance purchasers can experience increases in their income net of tax payments and insurance premiums when the costs associated with the sick are shed onto federal taxpayers. In standard models of self-interested voting behavior (Downs, 1957), this will translate into broad bases of support for such public insurance expansions. ${ }^{6}$

This cost-shedding result has novel implications for local public finance. In standard settings, states and localities are hindered from engaging in redistributive policies by the forces of fiscal competition (Tiebout, 1956). The wealthy may avoid small jurisdictions that tax progressively, for example, potentially undoing such redistributive efforts

\footnotetext{
4Medicaid can be targeted at unhealthy individuals through eligibility via disability or through income thresholds that explicitly take household medical spending into account. The latter approach is known as a medically-needy income concept. All 7 of the most tightly regulated states (see Table 1) were among the 35 states with Medically-Needy eligibility rules by 2000, with New York accounting for more than one-third of all Medically-Needy enrollment nation wide (Crowley, 2003).

${ }_{5}^{5}$ Cogan, Hubbard, and Kessler (2010) find evidence for a related phenomenon driven by asymmetric information within markets that permit premium adjustments due to pre-existing conditions.

${ }^{6} \mathrm{~A}$ median voter perspective on health-based redistribution at the national level has an interesting characteristic of its own. In contrast with the income distribution, where the "good" of income is concentrated among those at the top, the health-spending distribution is right skewed in the "bad." One might thus expect democratically expressed preferences to tilt in favor of substantial income-based redistribution and in opposition to substantial health-based redistribution.
} 
in general equilibrium (Feldstein and Wrobel, 1998). Similarly, the sick and poor may enter jurisdictions with generous Medicaid and cash-transfer programs, making such redistribution difficult to sustain (Peterson and Rom, 1990; Borjas, 1999).7 These forces encourage a "race to the bottom" in redistributive policies at the sub-national level (Oates, 1999). I show that, when coupled with federal cost sharing, community rating can turn this race to the bottom into a race to shed costs. The relevant forces will be particularly potent under the PPACA, which federalizes community rating and guaranteed issue rules and increases federal cost sharing in future Medicaid expansions. ${ }^{8}$

After developing the above theoretical results, I use the regulatory experience of the U.S. states to investigate the empirical importance of the relevant forces. Many states imposed some form of premium restrictions on their insurance markets during the early 1990s. A set of New England and Mid-Atlantic states stood out by implementing relatively pure community rating and guaranteed issue regimes in both the individual and small-group insurance markets. Later years ushered in substantial public insurance expansions, driven in part by the 1997 authorization of the State Children's Health Insurance Program (SCHIP). Beyond the SCHIP expansions, several of the most tightly regulated states made extensive use of Medicaid waivers to obtain federal funding for coverage of low-income and medically-needy adults. Public coverage of the disabled also increased significantly during this period.

I develop five new facts describing the evolution of insurance coverage in states that adopted strict regulatory regimes. I first find evidence of far more severe adverse selec-

\footnotetext{
7Peterson and Rom (1990) analyze implications of this "Welfare Magnates" hypothesis with a focus on its implications for state policy making and the location decisions of natives, while Borjas (1999) analyzes the location decisions of immigrants.

${ }^{8}$ Perhaps surprisingly, although purchase mandates work to stave off adverse selection, they may magnify the political economy pressures in favor of targeted public insurance expansions. By increasing the number of participants in the insurance market, mandates increase the number of voters who stand to benefit from shedding the costs associated with the sick onto federal taxpayers.
} 
tion pressures than documented by past research. ${ }^{9}$ Relative to the near-zero estimates in past research, I find that, within 3 years of adoption, coverage rates had fallen by 8-11 percentage points in tightly regulated markets relative to control markets. Past work has estimated the average effect of regulations over the years immediately following their implementation. Graphical evidence and dynamic regression estimates show that coverage declines escalate over this period; the medium run decline is thus much larger than the short run decline. This is not surprising, as even the rapid unraveling of a single insurance plan can take multiple years to unfold (Cutler and Reber, 1998).

Facts two through five relate to the interplay between regulations and the incidence of public insurance. The second fact is that, during the late 1990s and early 2000s, several of the tightly regulated states expanded their Medicaid programs much more extensively than the rest of the country. Third, these relatively large Medicaid expansions targeted unhealthy adults to a greater degree than public insurance expansions in other states. Fourth, consistent with a crowd-in effect, public insurance expansions were associated with private coverage recoveries in the tightly regulated markets, but not elsewhere. This resulted in large declines in the fraction of individuals without insurance in these markets. Finally, consistent with the mechanisms described above, the private market recoveries were largest in the states where Medicaid expansions were most effectively targeted at the unhealthy.

\footnotetext{
${ }^{9}$ This characterization of past findings may sound surprising given recent debate over the role of the insurance purchase mandate in the PPACA. In the debate over the PPACA, the law's supporters and opponents both tended to assume that insurance markets would severely unravel in the absence of the mandate provision. This view has support in the form of state-specific case studies and anecdotal reports. To the best of my knowledge, however, existing evidence in the peer reviewed economics literature on community rating does not support the typical, strongly stated version of this view. Papers finding nearzero coverage impacts include Buchmueller and DiNardo (2002), Simon (2005), Zuckerman and Rajan (1999), Herring and Pauly (2006), LoSasso and Lurie (2009), Davidoff, Blumberg, and Nichols (2005), Monheit and Schone (2004) and Sloan and Conover (1998). While these papers find little impact on total coverage rates, many nonetheless find evidence of shifts in coverage towards populations with high expected health spending. Several papers in this literature, including Buchmueller and DiNardo (2002), Buchmueller and Liu (2005), and LoSasso and Lurie (2009), find evidence that the implementation of community rating resulted in increases in the market share of Health Maintenance Organizations (HMOs).
} 
New York provides the most striking example of the experience described above. In 1993, New York adopted community rating and guaranteed issue regulations as strict as those in any state. Relative to comparable markets in other states, coverage rates in New York had fallen 8 percentage points from 1993 to 1997. Subsequently, New York aggressively expanded its Medicaid program, making disproportionate use of federal SCHIP appropriations (Herz, Peterson, and Baumrucker, 2008) and increasing adult enrollment, in particular for the sick, far more than the typical state through its Healthy NY and Family Health Plus programs. During these public insurance expansions, private coverage made up all of its losses (relative to control markets) from earlier years.

\section{Interplay between Regulations and Public Insurance}

This section characterizes the effect of comprehensive regulatory regimes, like that adopted by New York, on the incidence of public insurance programs. The exposition, which draws on the framework of Einav, Finkelstein, and Schrimpf (2007), is designed to build towards the relevant incidence formulas as sparsely as possible. ${ }^{10}$

\subsection{Basic Features of the Model}

Individuals are indexed by $i$ and live in jurisdiction $j$. They have concave utility in consumption out of wealth $(W)$ net of out-of-pocket health expenditures $\left(h^{o o p}\right)$, insurance premiums $\left(p_{i, j}\right)$, and tax payments $\left(\tau_{i, j}\right)$, so that $c=W-h^{o o p}-p_{i, j}-\tau_{i, j}$. The tax payment can be broken into jurisdiction-specific and federal components. Assuming "many" jurisdictions, each area's transfer programs have no impact on its residents' federal tax

\footnotetext{
${ }^{10}$ Many important features of insurance markets, including administrative costs, heterogeneity in consumer risk preferences, and moral hazard (both on the margin of health care consumption when sick and the margin of effort to avoid illness), are excluded because they do not directly influence this paper's central results.
} 
payments.

Individuals differ in terms of their probability of getting sick $\left(\beta_{i} \epsilon\left\{\beta_{1}, \beta_{2}\right\}\right.$ with $\beta_{1}<$ $\beta_{2}$ ), with fraction $\pi_{2}$ of the population having a high illness probability. When sick, an amount $h$ must be spent to cure the illness. Individuals may also differ in terms of wealth or some other determinant of eligibility for public insurance.

The insurance market involves a binary choice between purchasing full insurance and going uninsured. ${ }^{11} \mathrm{I}$ assume a standardized contract to gain insight into the extent to which pooling can be sustained and into the incidence of Medicaid expansions on individuals inside and outside this single pool. ${ }^{12}$ This focuses attention on the consumer's decision to participate in the insurance market, which is the principle margin analyzed in the empirical work.

Insurance companies sell full insurance in a competitive market, implying actuarially fair premiums. They know each individual's type, but may be restricted in using this information when setting premiums. Letting $r \in[0,1]$ describe the degree of community rating, type $i$ individuals face a premium of $p_{i, j}(r)=(1-r) p_{i, j}+r p_{c, j}$, where $p_{i, j}=\beta_{i} h$ and $p_{c, j}$ is the average experience-rated premium across private insurance purchasers. ${ }^{13}$ In this setting, type $i$ individuals purchase insurance if and only if $p_{i, j}(r)$ is less than some threshold premium $p_{i, j}^{*}{ }^{14}$ With constant absolute risk aversion, willingness to pay

\footnotetext{
${ }^{11}$ This is an important deviation from the canonical framework of Rothschild and Stiglitz (1976), hereafter RS. The rich contract space in the RS framework drives pooling equilibria out of existence. More recent work, including Crocker and Snow (1986), Rothschild (2007), and Finkelstein, Poterba, and Rothschild (2009), has focused on the welfare losses associated with endogenous contract choice in a community-rated environment.

${ }^{12}$ This is not an unreasonable characterization of the small-group market, where employees rarely have choice over multiple insurance products. Tabulations from the Medical Expenditure Panel Survey suggest that 76 percent of workers at firms with fewer than 100 employees are offered no more than one insurance plan. When an employer does not offer insurance, choices in the non-group markets of many states involve a limited number of standardized products.

${ }^{13}$ Pure community rating corresponds to the case where $r=1$, while pure experience rating corresponds to the case where $r=0$.

${ }^{14}$ This follows from the fact that utility when uninsured is constant in $p_{i, j}(r)$ while utility when insured
} 
for insurance becomes invariant to types' wealth endowments and tax payments.

\subsection{The Incidence of Community Rating}

Community rating generates transfers away from type 1 individuals when they purchase insurance. If the community-rated premium exceeds their willingness to pay, then type 1 individuals drop out of the insurance market. This occurs when the degree of community rating $(r)$ exceeds a threshold described by $r^{*}=\frac{p_{1, j}^{*}-p_{1, j}}{p_{c, j}-p_{1, j}}$. With a homogenous set of type 1 individuals, adverse selection is necessarily complete when it occurs at all. If type 1 individuals are heterogeneous in their degree of risk aversion, or if there are more than two types, partial pooling may occur.

\subsection{The Incidence of Medicaid Expansions}

In an adversely selected market, expansions of public health insurance will look more attractive, in particular to continuing market participants, than in a well-functioning market. We can initially see this by looking to Medicaid's relatively healthy direct beneficiaries. Absent adverse selection, healthy individuals purchase private insurance when they have no access to Medicaid. Medicaid thus increases the welfare of beneficiaries as an in-kind transfer that is equivalent to a premium subsidy, with the benefit described by $u\left(W_{i}-\tau_{i, j}\right)-u\left(W_{i}-\beta_{1} h-\tau_{i, j}\right)$. Community rating increases the size of the effective premium subsidy for these healthy individuals. If they have dropped out of the insurance market, then Medicaid replaces lost insurance value in addition to providing a transfer. The benefit under adverse selection is described by $u\left(W_{i}-\tau_{i, j}\right)-\left[\left(1-\beta_{1}\right) u\left(W_{i}-\tau_{i, j}\right)+\right.$ $\left.\beta_{1} u\left(W_{i}-h-\tau_{i, j}\right)\right]$, which exceeds the benefit in the experience-rated market. ${ }^{15}$

is strictly decreasing in $p_{i, j}$.

${ }^{15}$ This follows from a derivation of the fact that insurance is guaranteed to have positive net value to risk averse agents in this setting. 
I now consider the incidence of Medicaid expansions for non-recipients, focusing on markets that vary along two dimensions. The first is their degree of community rating, $r$. The second is the extent to which each jurisdiction's Medicaid program is self-financed, with $s$ describing the self-financed share. The total per capita cost of a jurisdiction's Medicaid program is described by:

$$
C_{j}=\operatorname{mcaid}_{2, j} p_{2}+\operatorname{mcaid}_{1, j} p_{1}
$$

The variable mcaid $_{2}$ is the fraction of the total population that is on Medicaid and has high expected costs. Similarly, mcaid $_{1}$ is the fraction of the total population that is on Medicaid and has low expected costs. These variables are defined such that mcaid $_{j}=$ mcaid $_{2, j}+$ mcaid $_{1, j}$ is the fraction of the jurisdiction's population that is on Medicaid. When jurisdiction $j$ must self-finance fraction $s_{j}$ of its own Medicaid costs, it satisfies its balanced budget constraint with a tax of $\tau_{j}=s_{j} C_{j}$.

\subsubsection{Financing Incidence}

In describing the effects of incremental Medicaid expansions, the fraction of new beneficiaries that are of type 2 , denoted $\rho$, emerges as an important parameter. The change in self-financed costs driven by an incremental expansion is described by:

$$
\frac{d \tau_{j}}{d m c a i d_{j}}=s_{j} \frac{d C_{j}}{d m c a i d_{j}}=s_{j}\left[\rho p_{2}+(1-\rho) p_{1}\right] .
$$

Equation (2) describes the financing incidence of a Medicaid expansion, which is incurred by all individuals in the jurisdiction.

In a purely experience-rated insurance market $(r=0)$, an increase in tax payments is the only channel through which Medicaid expansions affect non-beneficiaries. While the size of this tax increase can be blunted by federal cost sharing, the net welfare impact is 
unambiguously negative. This negative effect of Medicaid on those who are healthy and non-poor underlies the classic "race to the bottom" result in local public finance (Oates, 1999). For those participating in the insurance market, the welfare impact is described by:

$$
\begin{aligned}
\frac{d U_{i, j}}{d \text { mcaid }_{j}} & =-\frac{d \tau_{j}}{d m c a i d_{j}} u^{\prime}\left(W_{i}-\tau_{j}-p_{i, j}\right) \\
& =-s_{j}\left[\rho p_{2}+(1-\rho) p_{1}\right] u^{\prime}\left(W_{i}-\tau_{j}-p_{i, j}\right)<0 .
\end{aligned}
$$

\subsubsection{Insurance Market Incidence}

Under community rating, Medicaid expansions impact non-beneficiaries through insurance market incidence as well as financing incidence. Consider the case of pure community rating. Under pure community rating, the premium paid by all market participants can be written as

$$
p_{c, j}=p_{1}+\frac{\left(1-\pi_{1}-\text { mcaid }_{2, j}\right)\left(p_{2}-p_{1}\right)}{\left(1-\text { mcaid }_{2, j}-\text { mcaid }_{1, j}\right)}{ }^{16}
$$

Differentiating and re-arranging reveals that an incremental Medicaid expansion has the following impact on the community-rated premium:

$$
\frac{d p_{c, j}}{\text { dmcaid }_{j}}=\frac{p_{2}-p_{1}}{1-\text { mcaid }_{2, j}-\text { mcaid }_{1, j}}\left[-\rho+\frac{1-\pi_{1}-\text { mcaid }_{2, j}}{1-\text { mcaid }_{2, j}-\text { mcaid }_{1, j}}\right]
$$

If $\frac{d p_{c, j}}{d m c a i d}<0$, a Medicaid expansion will reduce community-rated premiums and may thus crowd in private coverage among those ineligible for public insurance. This occurs

\footnotetext{
${ }^{16}$ The expression conveniently describes the premium as a mark up over the fair premium for the type with low expected costs. The size of the mark up is increasing with the difference between the expected costs of the two types and with the share of market participants who are of the type with high expected costs.
} 
when the fraction of new Medicaid beneficiaries that has high expected costs exceeds the fraction of current insurance purchasers that has high expected costs:

$$
\rho>\frac{1-\pi_{1}-\text { mcaid }_{2, j}}{1-\text { mcaid }_{2, j}-\text { mcaid }_{1, j}} .
$$

\subsubsection{A Race to Shed Costs?}

The relationship between Medicaid expansions and community rated premiums has a novel implication beyond generating the possibility of crowding-in. This second implication relates to total welfare incidence. When Medicaid expansions are sufficiently targeted at unhealthy individuals, and when a sufficiently large share of Medicaid costs are financed by the federal government, their total impact on the welfare of non-beneficiaries is positive $\left(\frac{d U_{i, j}}{d m c a i d_{j}}>0\right)$. This is true when (6) and the following condition hold:

$$
s_{j}>\frac{1}{r} \frac{\left[\rho p_{2}+(1-\rho) p_{1}\right]}{\left[\frac{p_{2}-p_{1}}{1-\text { caid }_{2, j}-\text { mcaid }_{1, j}}\left(-\rho+\frac{1-\pi_{1}-\text { mcaid }_{2, j}}{1-\text { mcaid }_{2, j}-\text { mcaid }_{1, j}}\right)\right]} .
$$

When equation (7) holds, non-poor participants in private insurance markets benefit from Medicaid expansions through a premium reduction that exceeds the budgetbalancing increase in local taxes. Under these circumstances, the forces of fiscal competition push towards a race to shed the costs associated with unhealthy individuals onto federal taxpayers. After assessing the empirical relevance of these forces in Sections 2 through 6, this paper concludes with a discussion of their relevance in the context of the PPACA.

\section{The Evolution of State Health Insurance Regulations}

Over the last 20 years, U.S. states have engaged in substantial experimentation with health insurance regulations. As the Clinton Administration's health plan stalled during 
the early 1990s, many states adopted some form of community rating and/or guaranteed issue regulations. Community rating rules restrict insurers from adjusting premiums on the basis of an individuals's health status (and, to degrees that vary across states, on the basis of age and other demographic characteristics). Guaranteed issue rules prevent insurance companies from rejecting beneficiaries or limiting their coverage on similar bases.

Table 1 highlights states with at least some experience in community rating, separating them by their classification for this paper's empirical analysis. My criteria for categorizing a state as comprehensively regulated are two-fold. First, it must have modified or pure community rating rules, as defined by GAO (2003), in both its non- and small-group markets. Under pure community rating, premiums are only allowed to vary on the basis of family composition and geography; premium variations due to preexisting conditions and age are disallowed. Modified community rating allows (limited) premium variations on the basis of age, but disallows the use of pre-existing conditions. Many states allow premiums to vary within prescribed bounds (known as "rating bands") on the basis of pre-existing conditions. In practice, these bands significantly reduce the transfers associated with community rating, hence I do not consider such states to be comprehensively regulated. ${ }^{17}$

The second requirement is that the state must have guaranteed issue rules that go beyond the federal requirements in the 1996 Health Insurance Portability and Accountability Act (HIPAA) and the 1985 Consolidated Omnibus Budget Reconciliation Act (COBRA). This typically involves requiring shorter exclusion periods for pre-existing condi-

\footnotetext{
${ }^{17}$ Most state rating bands allow premiums to vary by at least 100 percent. For a typical family policy in the non-group market in 2002, this implies premium variation on the order of $\$ 4,400$ (see, e.g., Bernard and Banthin (2008)). The within-market transfers implied by the rating laws in such states will be much smaller than in states with pure community rating. Even in the minority of states with relatively tight rating bands (e.g., Washington), the implied transfers are on the order of $\$ 1$,ooo less than they would be under a community rating regime.
} 


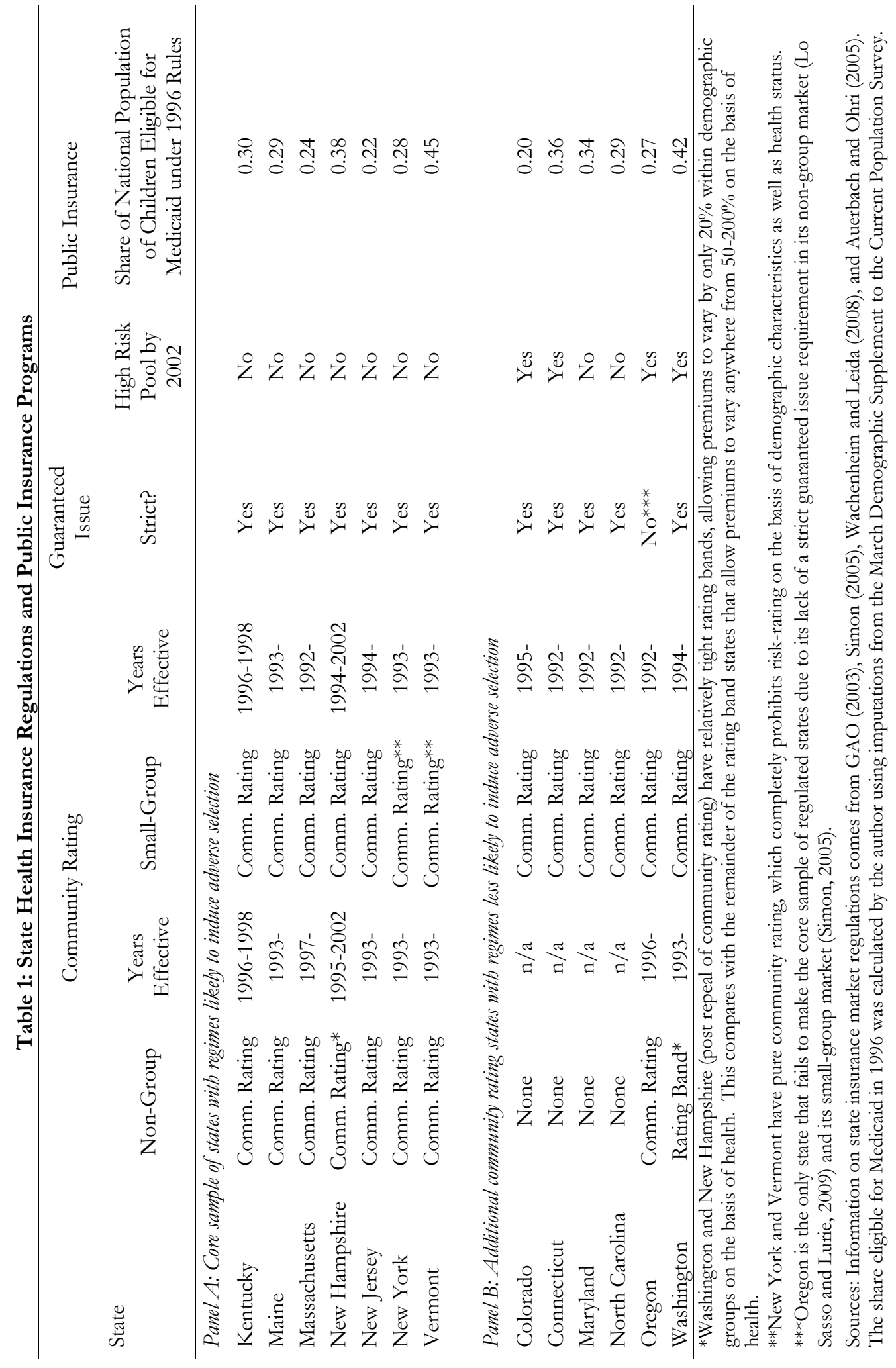


tions and longer periods of continuation coverage for those who lose health insurance due, among other reasons, to loss of employment. Guaranteed issue rules can also vary in terms of the range of products to which they apply, with the strictest regulations requiring guaranteed issue of all insurance products. For categorizing the stringency of a state's guaranteed issue requirements in the small- and non-group markets, I rely on Simon (2005) and LoSasso and Lurie (2009) respectively.

Data from the Medical Expenditure Panel Survey (MEPS) provide a sense for the implications of these regulations for the premiums of healthy households. The premium increases associated with comprehensive regulations are driven in large part by the health spending distribution's right tail. Absent public coverage of high cost households, a family in the bottom quintile of the health spending distribution would, on average, experience a premium increase of nearly 100 percent due to the implementation of pure community rating (from $\$ 2,700$ to $\$ 5,100$ ) if all households purchase insurance.

As shown in Table 1, I classify 7 states as adopting comprehensive regulations. Ordered chronologically, they are Maine, New York, Vermont, New Jersey, New Hampshire, Kentucky, and Massachusetts. Since these states are located in New England and the Mid-Atlantic (with the exception of Kentucky), the empirical work employs methods designed to allay concerns that arise with comparisons across groups of dissimilar states. Adoption years (defined as the first year in which a state's non- and small-group markets were both comprehensively regulated) range from 1993 to 1997 . Two of the states, Kentucky and New Hampshire, abandoned their comprehensive regulations during the sample. ${ }^{18}$

\footnotetext{
${ }^{18}$ Wachenheim and Leida (2007) report that Kentucky's regulations were legislated amidst substantial regulatory and legal uncertainty, with some provisions weakened before their enactment. Insurance companies exited the market in large numbers and repeal of the law began a mere two years after its enactment. Wachenheim and Leida also report that New Hampshire's law was repealed amidst widespread perceptions of declining coverage.
} 


\section{Approach to Estimating the Effects of Regulations}

Using individual-level data from the March Demographic Supplements to the Current Population Survey (CPS), I empirically examine the evolution of insurance coverage following states' adoption of comprehensive regulations. The non- and small-group markets governed by comprehensive regulations are the treated markets of interest. Equivalent markets in unregulated states can serve as controls within a difference-in-differences framework. The existing literature on community rating's initial effects includes estimates of this form as well as triple-difference estimates in which the large-group markets in all states serve as within-state control groups.

Comprehensive regulatory regimes were concentrated in the New England and Mid Atlantic census regions, which differ from other areas in terms of their populations' economic and demographic characteristics as well as the size of states' pre-regulation Medicaid programs. Consequently, this paper leads with an analysis that draws on the matching and synthetic control literatures. I confirm that these results are robust to a variety of specification and sample-selection checks within the more transparent doubleand triple-difference frameworks.

My initial analysis focuses on the post-regulation experiences of New York, Maine, and Vermont. For empirical purposes, there are two desirable features of the manner in which New York, Maine, and Vermont implemented their regulations. First, they regulated their non- and small-group markets simultaneously. This mitigates concerns that arise when estimating the effects of gradually implemented policies and allows for clean estimation of the regulations' dynamic effects. Second, they implemented their regulations in 1993, which was several years prior to late 1990s expansions in the availability of federal funds for financing Medicaid. This allows me to estimate the medium-run effect of comprehensive regulations prior to the occurrence of the public insurance expansions.

The matching analysis proceeds as follows. On a sample restricted to years prior 
to 1993 , I estimate the relationship between private insurance coverage and a broad set of household and individual-level economic and demographic variables. ${ }^{19}$ I then use the coefficients from this regression to estimate individuals' propensity to have private insurance coverage. I estimate these propensities for individuals from all years, including those subsequent to the adoption of New York, Maine, and Vermont's regulations. Using these propensity scores, I then form nearest neighbor matches (without replacement) between observations from treatment and control states. I match treatment and control observations when they occur during the same year and I exclude treatment observations from the sample if there are no control observations for which the difference in propensity scores is less than 0.0025 (roughly one one-hundredth of a standard deviation of the propensity score variable).

With the resulting samples, I then estimate the following equation:

$$
\begin{aligned}
\operatorname{COV}_{i, p, s, t} & =\sum_{y \neq 0} \delta_{y} \mathcal{1}\{\text { Years Relative To Enactment }=y\}_{y(s, t)}+\alpha_{p} I_{p} \\
& +\beta_{1_{s}} \text { State }_{s}+\beta_{2_{t}} \text { Year }_{t}+X_{i, s, t} \gamma+\varepsilon_{i, s, t} .
\end{aligned}
$$

$\mathrm{COV}_{i, p, s, t}$ is an indicator for whether or not individual $i$, associated with matched-pair $p$, who resides in state $s$ during year $t$ has private coverage or, in separate specifications, has public coverage or is uninsured. $X_{i, s, t}$ is the same vector of individual- and householdspecific characteristics that was utilized in the matching algorithm. The specification controls for full sets of year $\left(\right.$ Year $\left._{t}\right)$ and state $\left(\right.$ State $\left._{s}\right)$ indicator variables, as well as a set of indicators for the matched pairs $\left(I_{p}\right) \cdot{ }^{20} 1\{\text { Years Relative To Enactment }=y\}_{y(s, t)}$ is a set of indicator variables for the number of years since (or before) comprehensive regulations

\footnotetext{
${ }^{19}$ This sample also consists solely of participants in non- and small-group insurance markets, meaning that it excludes households with members who work at large firms.

${ }^{20}$ The results are ultimately robust to excluding the set of pair indicators, to excluding $X_{i, s, t}$, and to excluding both $X_{i, s, t}$ and the set of pair indicators.
} 
were enacted in a state. ${ }^{21}$

The coefficients of interest are the $\delta_{y}$. These coefficients are estimates of coverage changes in comprehensively regulated markets net of coverage changes in other markets. Since $y=0$ is the excluded time period, these changes are estimated relative to the year in which comprehensive regulations were adopted.

I next confirm that the results from estimating equation (8) are robust to two types of specification changes. The first involves using participants in large-group insurance markets, which were not directly affected by states' regulatory changes, to control for state-specific changes in economic conditions within a standard triple-difference estimation framework (Buchmueller and DiNardo, 2002). The second involves altering the criteria used to select the control group. These specifications, which estimate the differential evolution of coverage in comprehensively regulated markets net of differential coverage changes in states' large-group markets, take the following form:

$$
\begin{aligned}
& \mathrm{COV}_{i, s, t}=\beta_{1} \text { Post }_{t} \times \text { RegulatedState }_{s} \times \text { SmallFirm }_{i} \\
& +\beta_{2_{s}} \text { State }_{s} \times \text { SmallFirm }_{i}+\beta_{3_{s, t}} \text { State }_{s} \times \text { Year }_{t}+\beta_{4_{t}} \text { Year }_{t} \times \text { SmallFirm }_{i} \\
& +\beta_{5_{s}} \text { State }_{s}+\beta_{6} \text { SmallFirm }_{i}+\beta_{7_{t}} \text { Year }_{t}+X_{i, s, t} \phi+\varepsilon_{i, s, t} .
\end{aligned}
$$

$C O V_{i, s, t}$ is again an indicator for the coverage status (private coverage, public coverage, or uninsured) of individual $i$ who resides in state $s$ in year $t$. In addition to the usual vector of individual- and household-specific characteristics $\left(X_{i, s, t}\right)$ I control for the essential features of triple-difference estimation. These include full sets of year $\left(Y_{e a r_{t}}\right)$ and state $\left(\right.$ State $\left._{S}\right)$ indicator variables as well as an indicator for being on the non- and small-group insurance markets $\left(\right.$ SmallFirm $\left._{i}\right)$. The two-way interactions of these main effects are also essential; they account for differential trends across treatment and control states as well

\footnotetext{
${ }^{21}$ These variables are set equal to o for all years in states that never adopted comprehensive regulations.
} 
as across the large- and small-group markets. They also allow the difference between large- and small-group markets to differ at baseline across the states.

I estimate equation (9) and its difference-in-differences counterpart to confirm the results, namely a pattern of coverage declines followed by recoveries, obtained from estimating equation (8). ${ }^{22} \mathrm{I}$ do this with two distinct sets of estimates. The first captures the decline in coverage from the pre-regulation period to its nadir and the second capturing the change in coverage from the nadir to the end of the sample. Guided by the raw data and by results from estimating (8), I use data from 1996 and 1997 to describe the nadir.

The analysis in Section 1 showed that Medicaid expansions can explain private coverage recoveries in community-rated markets when they disproportionately cover high cost individuals. The data allow me to take an additional step towards linking the coverage recoveries to this mechanism. I use the following specification to descriptively estimate the relationship between private coverage and public coverage for unhealthy adults (conditional on the extent of public coverage for healthy adults):

\footnotetext{
${ }^{22}$ The triple-difference framework may appear to be the superior estimation framework because it explicitly controls for within-state trends. In practice, measurement error results in contamination between the within-state treatment and control groups for two reasons. First, the small- and large-group markets cannot be cleanly segregated using firm-size data from the CPS. Second, not all individuals classified as being on the large-group market (due to a household member's employment at a firm with more than 100 employees) will have access to large-group insurance. Data from the Medical Expenditure Panel Survey (MEPS) suggest that roughly 8 percent of those in families with employment at large firms were not offered employer-provided insurance, putting them on the non-group insurance market. Both sources of measurement error will attenuate the triple-difference estimates towards o. Additionally, regulations may have spillover effects which impact within-state large-group markets. For example, the regulations may lead insurance companies to leave a state altogether or to raise premiums in the large-group market as a means of cross-subsidizing "loss leader" products in the non- and small-group markets. (The latter behavior could be profit maximizing in states like New York, where HMOs must offer products in the non- and small-group markets if they desire to participate in the large group market.) Such spillovers would also tend to bias results towards zero in the triple-difference framework. On this point, in analysis available on request, I have not found evidence that community rating regulations shifted employment (either in aggregate or selectively of the healthy) away from small firms.
} 


$$
\begin{aligned}
\text { COV }_{i, s, t} & =\beta_{1} \text { UnhealthyFracMcaid }_{s, t} \times \text { RegulatedState }_{s}+\beta_{2} \text { UnhealthyFracMcaid }_{s, t} \\
& +\beta_{3} \text { HealthyFracMcaid }_{s, t} \times \text { RegulatedState }_{s}+\beta_{4} \text { HealthyFracMcaid }_{s, t} \\
& +\beta_{5_{s}} \text { State }_{s}+\beta_{6_{t}} \text { Year }_{t}+\beta_{7_{t}} \text { RegulatedState }_{s} \times \text { Year }_{t}+X_{i} \gamma+\varepsilon_{i, s, t} .
\end{aligned}
$$

The last row of equation (10) contains the components of standard difference-indifferences estimation, where the coefficients of interest would be the $\beta_{7_{t}}{ }^{23}$ Here I use the set of RegulatedState $\times$ Year R $_{t}$ indicators to control for changes common to the set of regulated markets. This allows me to estimate the relationship between Medicaid and private coverage within this set of comprehensively regulated markets. The principal coefficient of interest is $\beta_{1}$, which describes the relationship between private coverage and Medicaid's coverage of unhealthy adults (UnhealthyFracMcaid = \# of Unhealthy Adults on Medicaid $)$ in a comprehensively regulated state relative to other states. ${ }^{24}$

I note up front that $\beta_{1}$ should be given a predictive, rather than causal, interpretation because variation in UnhealthyFracMcaid is not exogenous. I estimate equation (10) to explore the plausibility of the proposed mechanism. If expansions in Medicaid's coverage of unhealthy adults (conditional on its coverage of healthy adults) are uncorrelated with private coverage in the regulated markets, it would be difficult to argue that such expansions played a role in driving the coverage recoveries. It is also worth noting that a strong, positive correlation must overcome the most obvious sources of bias, which would tend to produce negative correlations between private coverage and Medicaid coverage

\footnotetext{
${ }^{23}$ That is, the last row contains the difference-in-differences counterpart of equation (9), for which I also report results.

${ }^{24}$ UnhealthyFracMcaid is equivalent to mcaid $_{2}$ from Section 1 , where the subscript 2 indicated a high illness probability. Similarly, HealthyFracMcaid $=\frac{\text { \# of Healthy Adults on Medicaid }}{\text { \# of Adults in the Population }}$ is equivalent to mcaid $_{1}$.
} 
of any kind. ${ }^{25}$

I also estimate the relationship between private coverage and the extent to which states' Medicaid programs target unhealthy adults as follows:

$$
\begin{aligned}
\operatorname{COV}_{i, s, t} & =\beta_{1} \rho_{s, t} \times \text { RegulatedState }_{s}+\beta_{2} \rho_{s, t} \\
& +\beta_{3} \text { TotFracMcaid }_{s, t} \times \text { RegulatedState }_{s}+\beta_{4} \text { TotFracMcaid }_{s, t} \\
& +\beta_{5_{s}} \text { State }_{s}+\beta_{6_{t}} \text { Year }_{t}+\beta_{7_{t}} \text { RegulatedState }_{s} \times \text { Year }_{t}+X_{i} \gamma+\varepsilon_{i, s, t} .
\end{aligned}
$$

I estimate equation (11) with and without including the control for TotFracMcaid ${ }_{s, t}=$

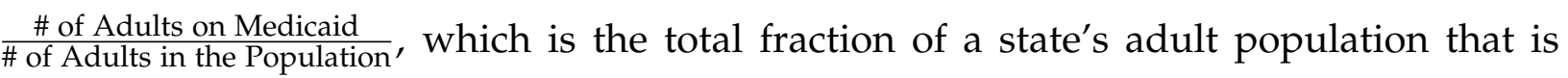
covered by Medicaid. I construct $\rho_{s, t}$ as $\frac{\text { UnhealthyFracMcaid }_{s, t}}{\text { TotFracMcaid }_{s, t}}$. This variable quantifies the fraction of a state's adult Medicaid population that is unhealthy. Although we must again give $\beta_{1}$ a predictive rather than causal interpretation, potential sources of bias are less obvious here than in estimating equation (10). ${ }^{26}$ The test that $\beta_{1}>0$ is this paper's best test for the relevance of the mechanisms described in Section 1.

\section{Data and Baseline State Characteristics}

The empirical analysis uses samples of individuals from the March Demographic Supplements to the Current Population Survey (CPS) for years 1988-2007. These surveys provide information on insurance status and key household economic and demographic

\footnotetext{
${ }^{25}$ Specifically, unhealthy individuals may take up Medicaid due to adverse economic conditions or expansions of Medicaid eligibility for the general population. In either case, one would expect increases in Medicaid coverage for unhealthy individuals to be correlated with declines in private coverage.

${ }^{25}$ TotFracMcaid is equivalent to mcaid from Section 1.

${ }^{26}$ There are standard reasons (discussed above) to worry that the fraction of the population on Medicaid is driven by unobservable economic factors. It is less obvious, however, why unobservable factors would be correlated with the fraction of Medicaid beneficiaries who are unhealthy. There is even less reason to think that, if such unobservables existed, they would differ systematically across states that did and did not adopt comprehensive regulations.
} 
information for years 1987-2006. I focus on individuals in households with at least one child and with at least one full-time employed adult. This places attention on a) families that are active participants in insurance markets and b) the market segments that were most directly affected by changes in Medicaid eligibility over this time period. ${ }^{27}$

The matching and differencing estimation frameworks described in the previous section rely on the standard assumption that the treatment and control groups would have followed parallel trends in the absence of the relevant policy interventions. Since comprehensive regulations were non-randomly adopted, with adoption concentrated in the New England and Mid-Atlantic census regions, this assumption cannot be taken for granted. The summary statistics in Table 2 highlight pre-regulation differences between the treatment and control states that merit further attention. The full samples described in columns 1 and 2 reveal two relevant differences between these groups of states. The first visible difference is that the treatment states had higher rates of Medicaid coverage than did control states (10.5\% vs. $7.5 \%)$. The second visible difference is that treatment states also had relatively high private coverage rates ( $73.8 \%$ vs. $68.4 \%)$. Taken together, these differences resulted in a 7 percentage point difference in the fraction of individuals without insurance during the pre-regulation period (1987 to 1992). ${ }^{28}$

Panels A, D, and G of Figure 1 illustrate that, in spite of these level differences, coverage rates followed parallel pre-regulation trends in the treatment and control states. While this is reassuring, the plausibility of the parallel trends assumption can be bolstered by using matching methods to generate samples that have similar levels as well as trends. Comparisons of the treatment and control groups in samples generated us-

\footnotetext{
${ }^{27}$ Since community rating regulations treat households with and without children as separate market segments, the limited expansions of Medicaid for childless adults would not have affected premiums for those purchasing family policies.

${ }^{28}$ The sum of the population fractions with private coverage, with Medicaid coverage, and with no insurance exceed 1 because some individuals report being on both Medicaid and private coverage over the course of the year.
} 


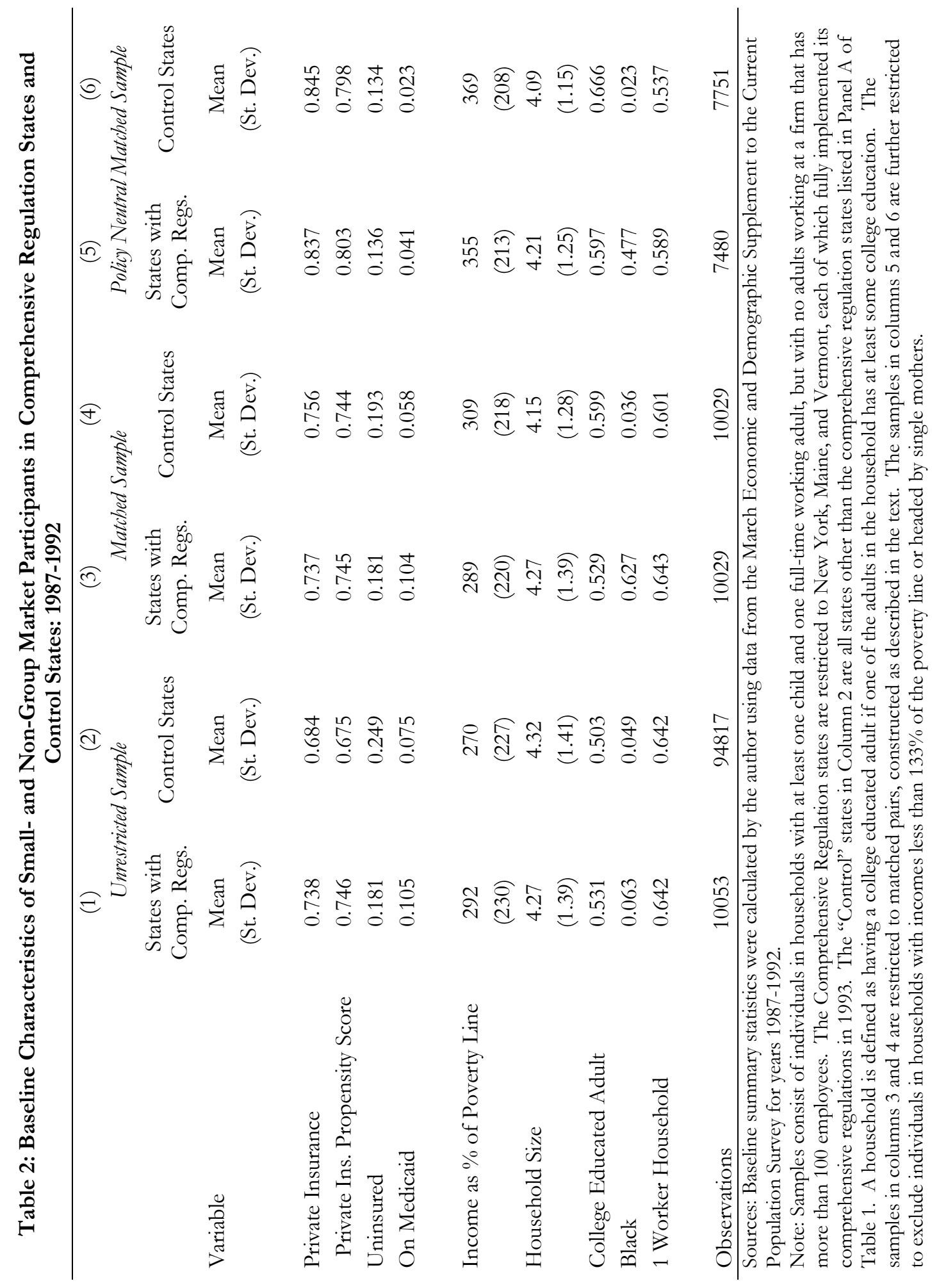


ing matching methods can be found in columns 3 through 6 of Table 2. The samples in columns 3 and 4 are restricted to nearest-neighbor matches based on estimates of individuals' propensity to have private insurance. These samples match quite closely in terms of the fraction uninsured and the fraction with private insurance. However, there is still a significantly higher probability that individuals in treatment states had Medicaid coverage at some point during a given calendar year. ${ }^{29}$ The samples in columns 5 and 6 exclude individuals in households that either have incomes less than $133 \%$ of the poverty line or that have a single mother as the household head. These are the primary groups for which Medicaid eligibilty varied across the treatment and control states, and this restriction brings the difference between the treatment and control groups below 2 percentage points. Exclusion of these groups also generates a sample that is unlikely to have been affected by policy changes associated with the implementation of welfare reform in 1996. The remaining panels of Figure 1 provide evidence of parallel pre-regulation trends for each of these samples.

Differences in the socioeconomic characteristics of the treatment and control samples merit additional discussion. Conditional on measured socioeconomic characteristics, individuals are more likely to have private coverage in the treatment states than in control states. To adjust for this I allowed the relationship between insurance coverage and variables related to income, race, and household structure to vary across the census regions. ${ }^{30}$ I chose the degree of flexibility to ensure that the treatment and control samples match on their baseline coverage rates when they match on their average propensity scores. This is indeed the case in columns 3 through 6 of Table $2 .{ }^{31}$ Differences be-

\footnotetext{
${ }^{29} \mathrm{~A}$ modestly larger share of individuals in the comprehensively regulated states had both public and private coverage at some point during the relevant calendar years.

${ }^{30}$ The same set of interactions between these socioeconomic variables and census-region indicator variables are used as control variables throughout the analysis.

${ }^{31}$ When I do not allow these relationships to vary across regions, samples with the same average propensity score tend to yield significantly higher baseline private coverage rates in the treatment group
} 
tween the treatment and control states highlight the importance of robustness analysis in this setting. The fact that the results are ultimately consistent across specifications that use unrestricted samples, samples matched on coverage propensities, and samples matched on state-level economic and demographic characteristics contributes to the persuasiveness of the evidence. Importantly, none of these sample selection procedures yield evidence that calls the validity of the parallel trends assumption into question.

\section{Analysis of Insurance Coverage Rates}

Panels A, B, and C of Figure 1 show the evolution of the fraction of individuals that has neither private nor public insurance in the treatment and control groups. These panels provide a stark depiction of two of this paper's central empirical findings. In large-group markets everywhere and in the small- and non-group markets of unregulated states, Medicaid expansions and declines in private coverage have roughly offset one another. The fraction of individuals without insurance changed little in these markets throughout the sample (1987-2006). In contrast, the comprehensively regulated small- and non-group markets followed quite different paths. After New York, Maine, and Vermont adopted comprehensive regulations in 1993, the fraction uninsured in the unrestricted sample (Panel A) increased by around 70\%, from 0.18 to around 0.31 in 1997. This erosion reversed in subsequent years, with the fraction uninsured declining to 0.14 by 2004 .

Panels D, E, and F of Figure 1 are similar to Panel A, B, and C, but report the fraction of the population covered by private insurance. Private coverage rates turn sharply for the worse in the comprehensive-regulation states from 1993-1996. After 1997 these markets show signs of recoveries, with the recoveries appearing to be complete in the

than in the control group. 

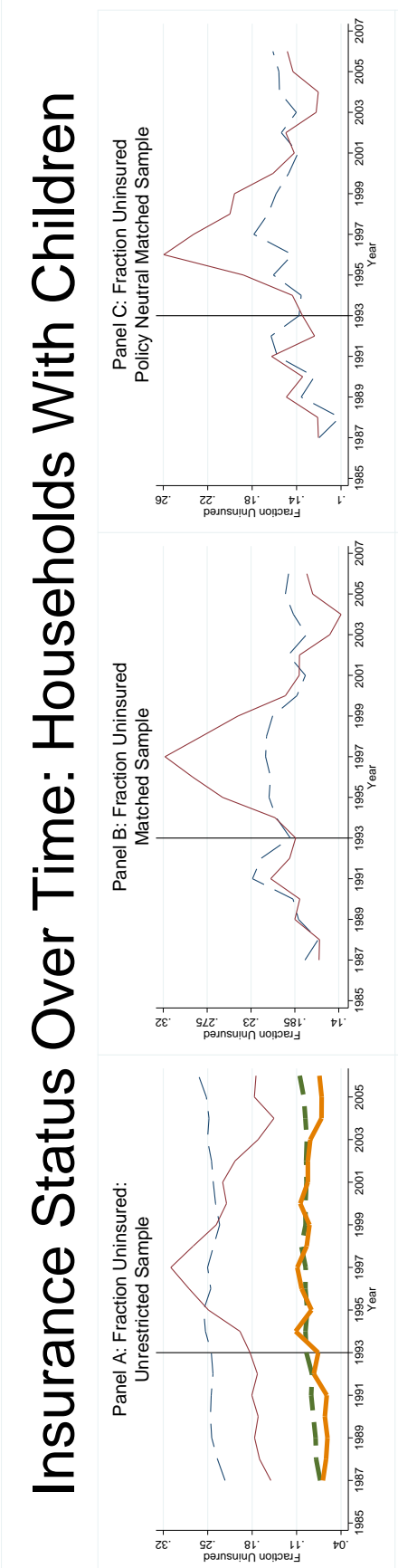
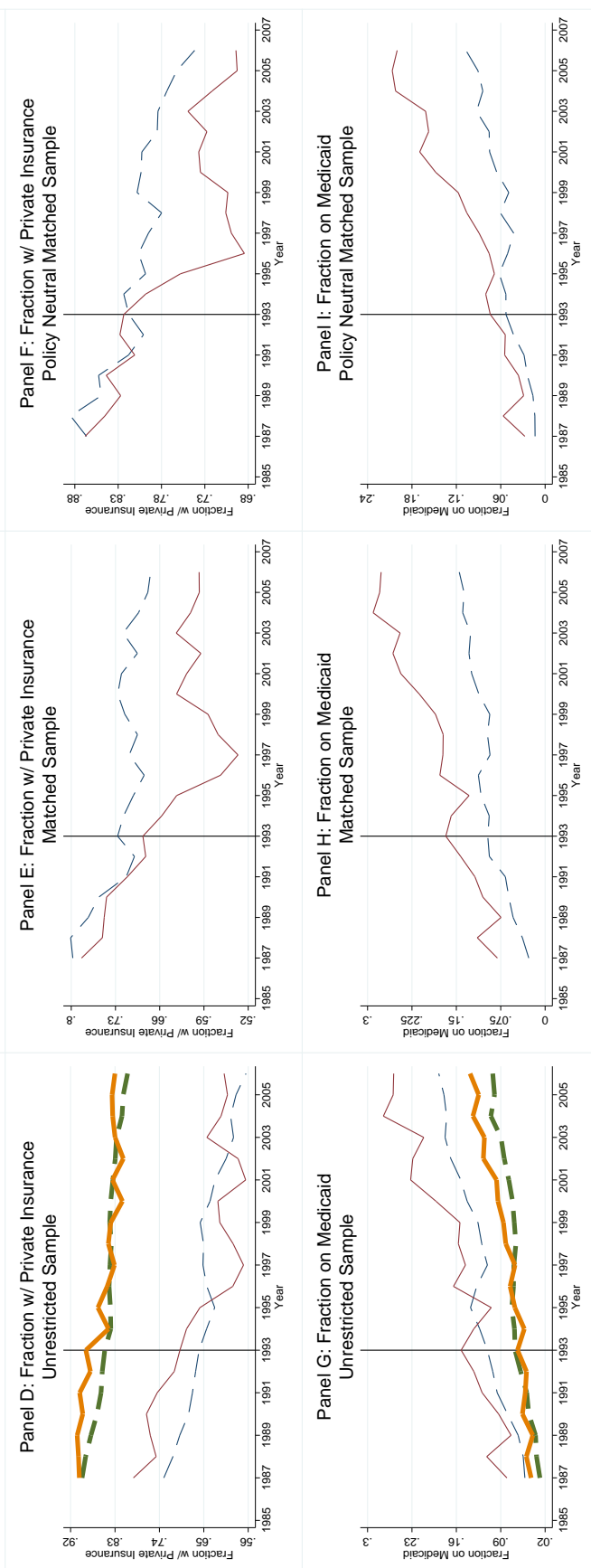

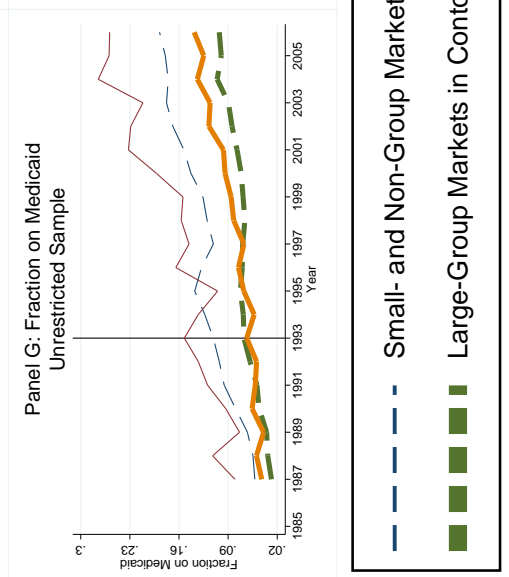

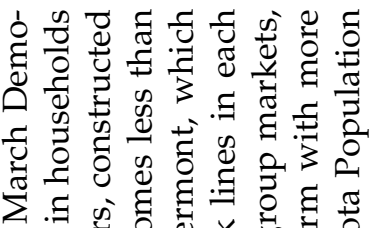

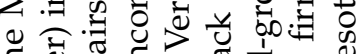

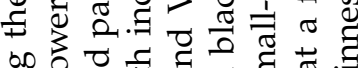

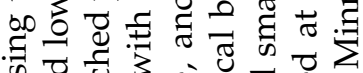

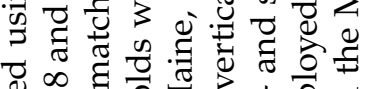
क्ष

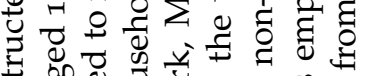
कo

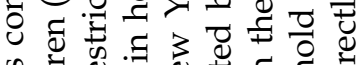

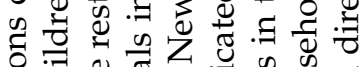

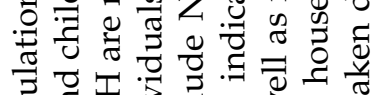

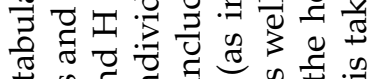

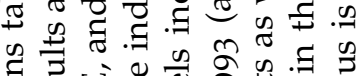

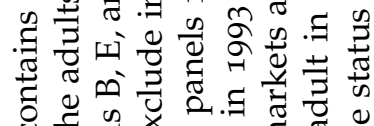
政

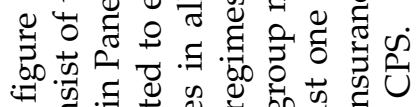
क ज्ञ E 0.

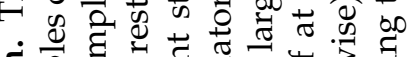

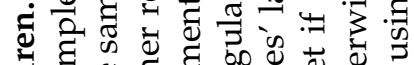

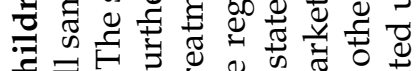

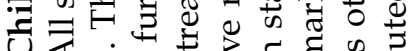
Uदें की

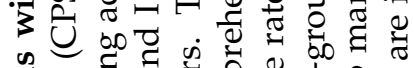
卷危要

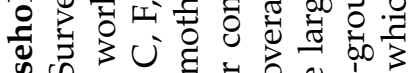
की

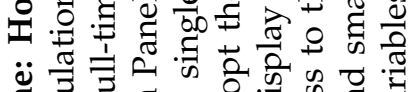

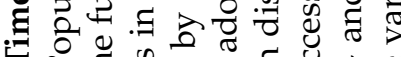

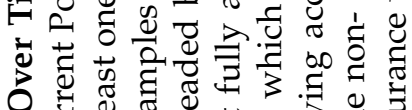

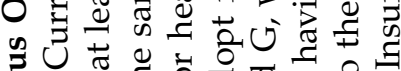

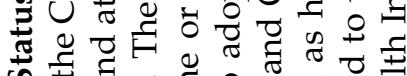
के

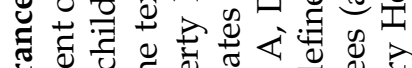

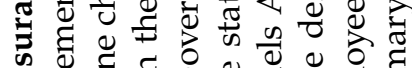

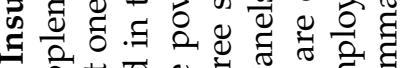

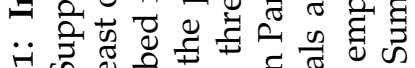
$\rightarrow$ क 记

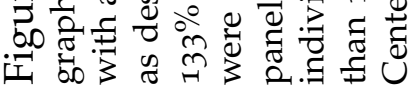


unrestricted sample and partial in the matched samples. In Panel F, for example, coverage rates are equal prior to the implementation of comprehensive regulations, decline by an excess of 12 percentage points in the regulated markets between 1993 and 1996, and remain down by an excess of 4 or 5 percentage points by the last four years of the sample.

A look across the panels of Figure 1 highlights an important point. Following 1997, the comprehensively regulated markets experienced sharp declines in the fraction of individuals without insurance. The sharpness of this decline results from the fact that both the fraction of individuals covered by Medicaid and the fraction of individuals with private insurance increased in these markets relative to other markets. This positive correlation is unique across time periods and market types, as public insurance's tendency to crowd out private insurance typically dominates the relationship between these forms of coverage (see, e.g., Cutler and Gruber (1996) and Gruber and Simon (2008)). This is initial, suggestive evidence that public insurance expansions can be implemented in ways that produce "crowding-in" effects when adverse selection has occurred in an insurance market.

\subsection{The Evolution of Coverage in Maine, New York, and Vermont}

Table 3 presents estimates of equation (8) using the treatment and synthetic control samples whose baseline characteristics were described in Table 2. The results reflect the evolution of coverage depicted in Figure 1. By 3 and 4 years following the adoption of comprehensive regulations (i.e., by 1996 and 1997) private coverage rates had declined on the order of 8 to 1o percentage points. The fraction uninsured had increased by similar, but modestly smaller magnitudes. ${ }^{32}$ Towards the end of the sample, the fraction unin-

\footnotetext{
${ }^{32}$ The smaller magnitudes reflect the averaging together of 1996 and 1997. The fraction uninsured peaked in individual years in the two samples, while the fraction with private coverage was close to its nadir in both years.
} 
sured returns to its pre-regulation levels. This comes from a combination of increases in public coverage, as demonstrated by the positive and statistically significant coefficients at the bottoms of columns 5 and 6 , and through partial recoveries of private coverage. The recovery of private coverage is largest with the full matched sample. For the sample that excludes individuals with incomes less than $133 \%$ of the poverty line, most of the decline in the fraction uninsured comes through increases in Medicaid coverage. This sub-sample is more strongly weighted towards households with members who would have become eligible for Medicaid during the latter half of the sampling frame. 33

The coverage declines observed through 1996 and 1997 are much larger than estimates found elsewhere in the literature on insurance-market regulations. While this is due in part to the sample's exclusion of childless adults, it is primarily due to the distinction between instantaneous and medium-run impacts. ${ }^{34}$ Past work has averaged its estimates of the effects of premium regulations across several years following their implementation. Since adverse selection spirals take time to unfold (see, e.g., Cutler and Reber (1998)), this will understate the full impact of implementing regulations. The samples in earlier work also tended to end prior to 1997 (see, e.g., Buchmueller and DiNardo (2002), and Simon (2005)), which was a year during which the regulated markets performed poorly. If I average across post-reform years, end the sample in 1996, and include childless adults, I come close to replicating the results from prior work.

\footnotetext{
33Prior to Medicaid expansions for children during the early 2000s, this group also experienced a substantial recovery in their private coverage rates, as can been seen by comparing the coefficient of .0386, which corresponds to years 2001 and 2002, with the low of -0.0854 experienced during 1996 and 1997.

34I focus on households with children because state Medicaid expansions for single adults were modest. It is the interaction of these Medicaid expansions with state regulatory environments that is this paper's focus.
} 


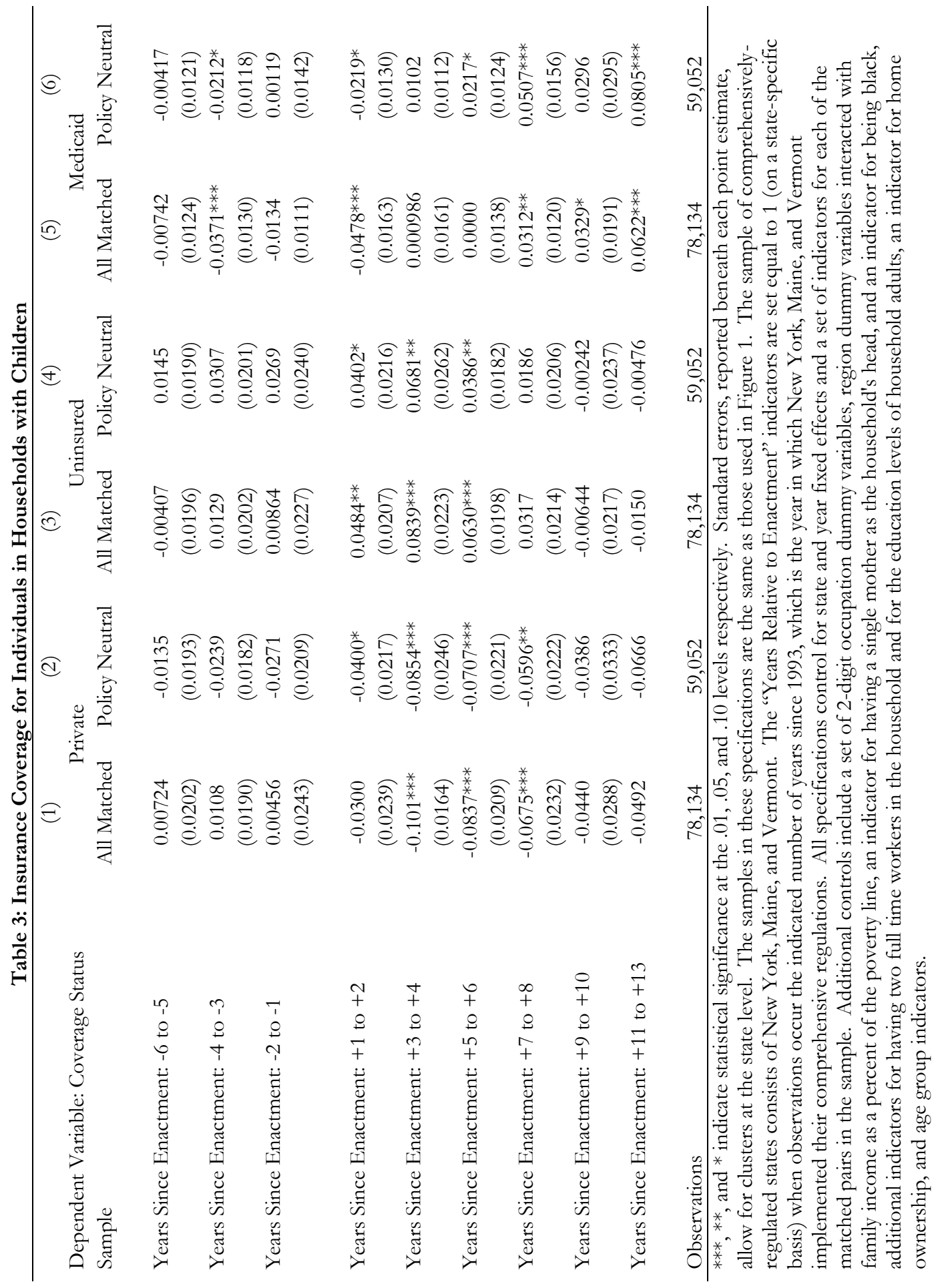




\subsection{Medicaid Expansions in Maine, New York, and Vermont}

I next present a more detailed characterization of differences between the Medicaid expansions of the comprehensively regulated states and the control states. All states expanded their Medicaid programs substantially for children following the authorization of SCHIP in 1997. Medicaid coverage of both children and adults are displayed in Panels G, H, and I of Figure 1 and in the regressions reported in columns 5 and 6 of Table 3. In this section I focus on Medicaid expansions for adult populations, which were relatively discretionary from the perspective of state governments. In addition to examining the total size of these expansions, I focus on differences in the extent to which Medicaid expanded for healthy and unhealthy adults. I define individuals as unhealthy if their 5-category self-reported health status is 3 or worse or if they report a work-limiting disability. 35

Figure 2 displays the fraction of adults on Medicaid both in total (Panels A, B, and C) and, for years in which measures of health status are available, by health status (Panels D, E, and F). Although the comprehensively regulated states had more extensive adult Medicaid coverage throughout the sample period, coverage rates moved on roughly parallel trends during the first half of the sample. Coverage rates appear to diverge around 2000, with substantial increases concentrated on relatively unhealthy adults with low incomes. Between 1999 and 2006, coverage rates for the full matched sample of adults (Panel B) rose by roughly to percentage points across Maine, New York, and Vermont and by 2 percentage points elsewhere. These increases were concentrated among those with incomes less than $300 \%$ of the poverty line, for whom coverage rates rose by 17 percentage points in the comprehensively regulated states and by 6 percentage points elsewhere. Increases for healthy and unhealthy adults were of comparable size in control states. In the comprehensively regulated states, on the other hand, coverage of unhealthy adults

35This accounts for roughly one third of the adult population. 

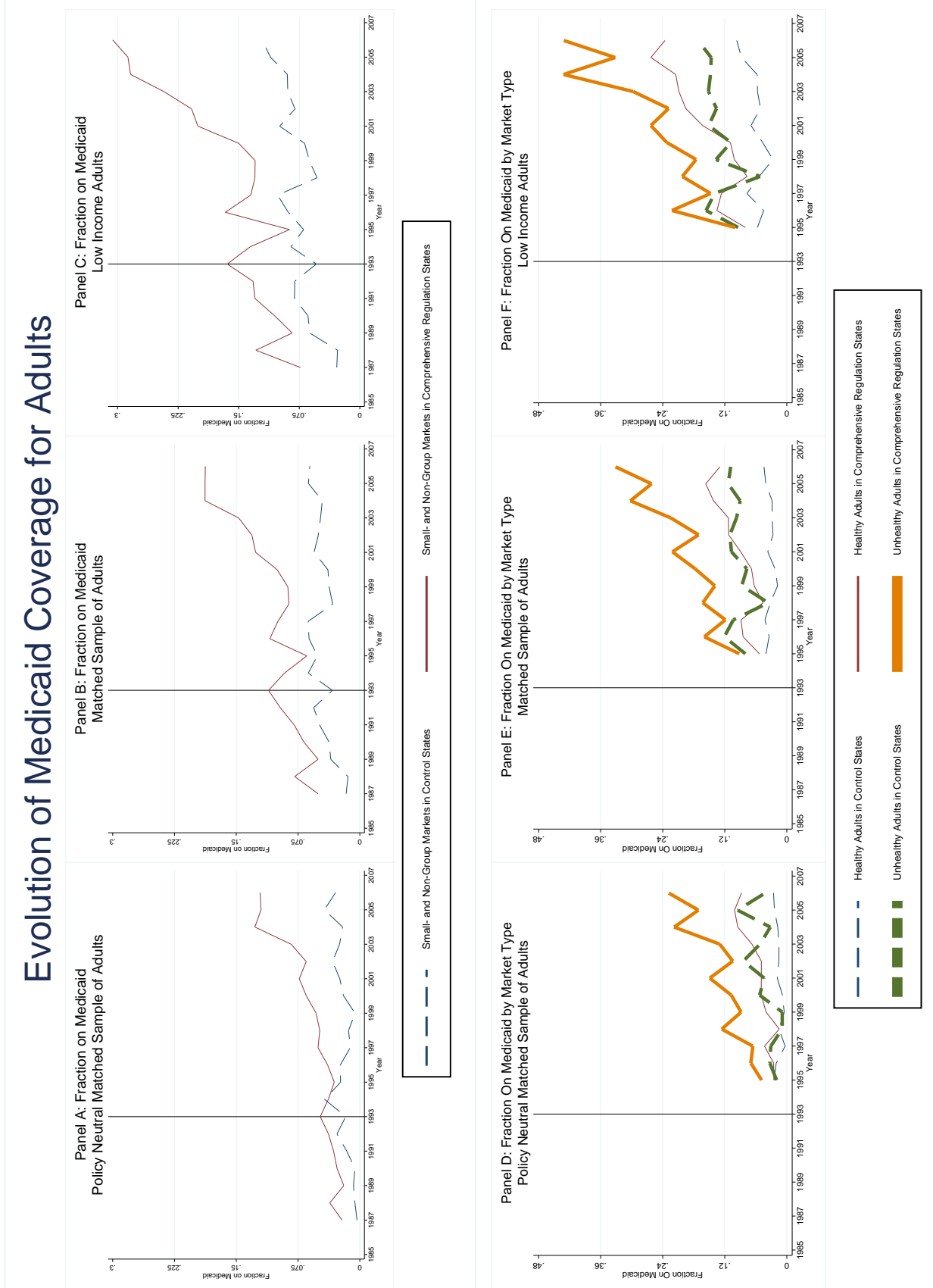

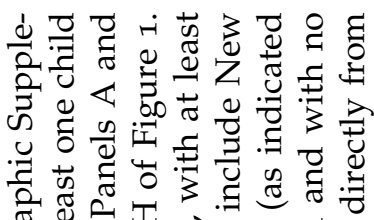

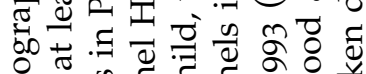
द्व ๑ चี

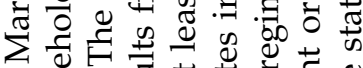

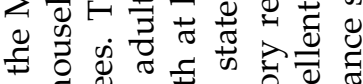

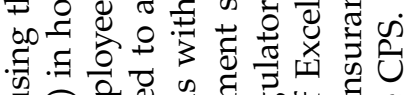

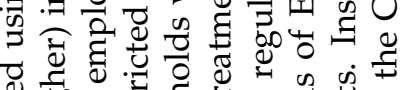
Ð

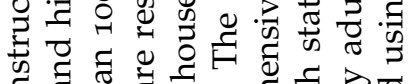
రี ปู่

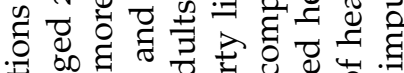

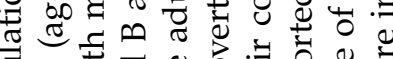

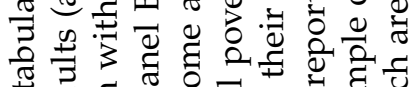

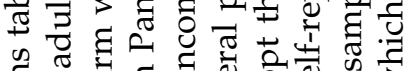
च 开

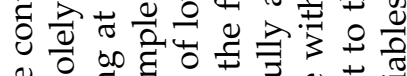

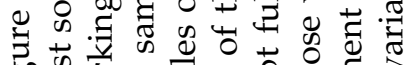
जo.

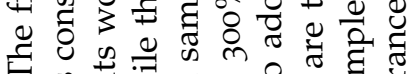

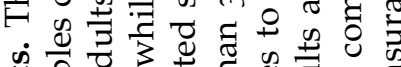

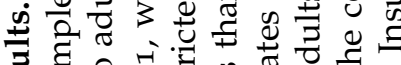

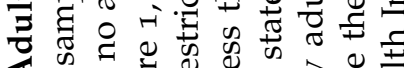

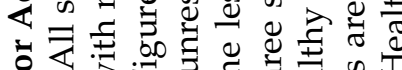

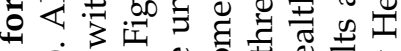

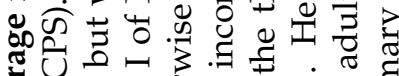

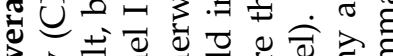

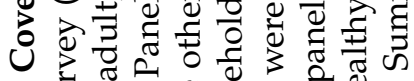
. ฮี ช。

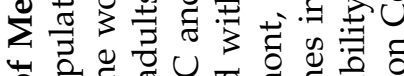

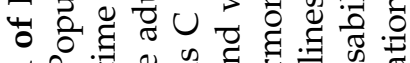

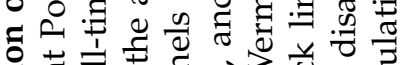

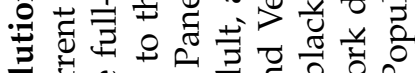

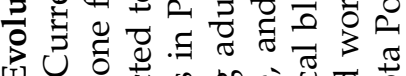
1 0 U

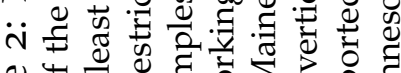
せ

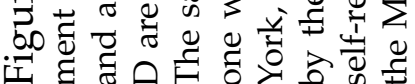




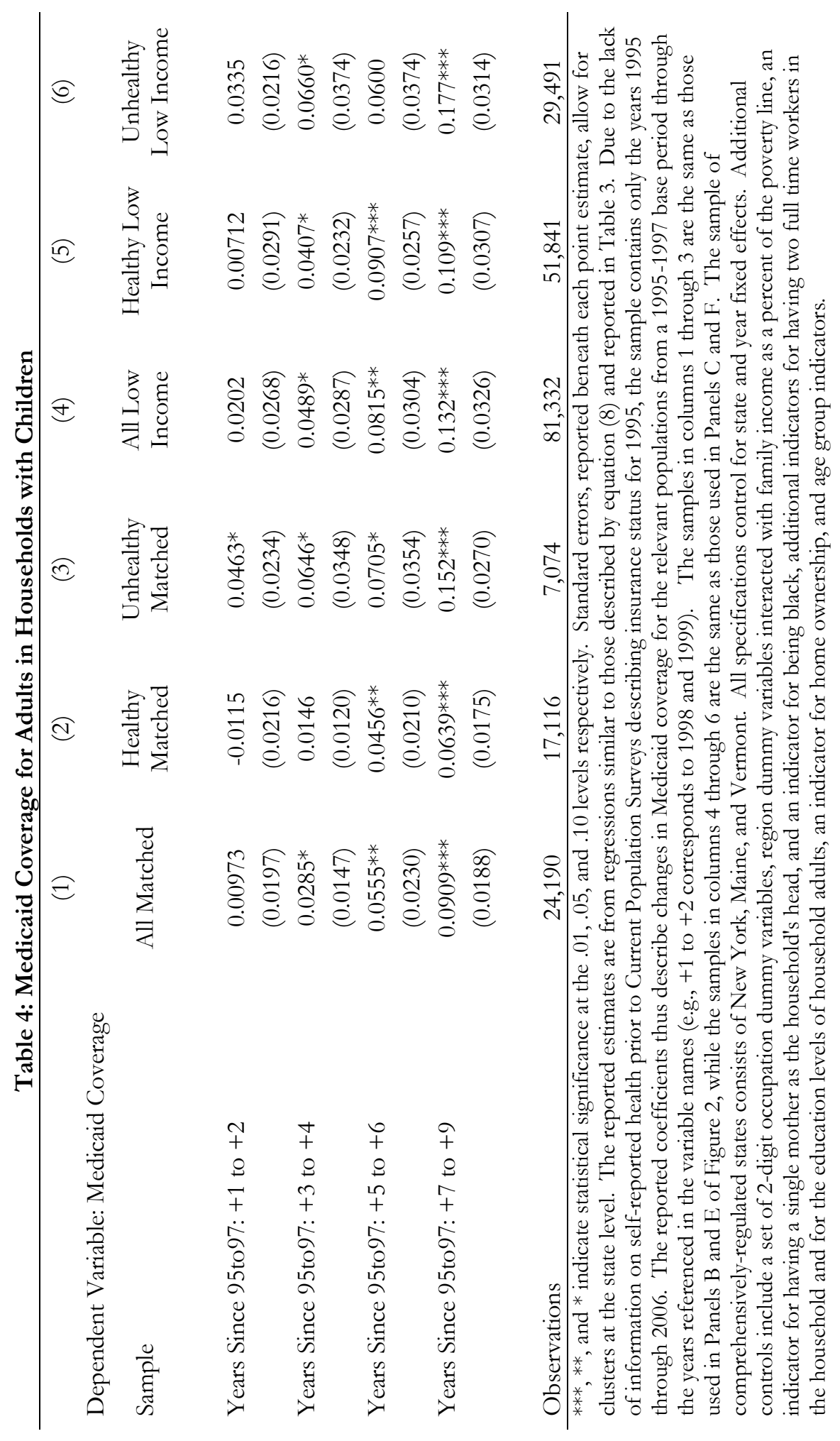


with low incomes rose by more than 20 percentage points while coverage of healthy adults with low incomes rose by roughly 12 percentage points. The regression results presented in Table 4 confirm that these differences in the evolution of Medicaid coverage are not driven by observable changes in the economic and demographic characteristics of individuals in the sample. ${ }^{36}$

\subsection{Coverage Changes in All Comprehensive Regulation States}

In this section I expand the set of treatment states to include those that adopted comprehensive regulations during the mid-1990s, namely New Jersey, New Hampshire, Kentucky, and Massachusetts. In describing the evolution of insurance coverage for the broader group of states, I estimate equation (9). I first estimate specifications in which 1987 through 1992 describe the "pre" period and 1996 and 1997 describe the low point after the adoption of regulations. I then estimate specifications in which 1996 and 1997 describe initial low points while 2003 through 2006 describe the period following the public insurance expansions of the late 1990s and early 2000 .

Tables 5 and 6 present the results. Table 5 presents changes in private insurance coverage and in the fraction of individuals without insurance. Table 6 presents changes in Medicaid coverage. The results in Panels A (triple-difference specifications) and B (difference-in-differences specifications) show that the full set of states with comprehensive regulations experienced coverage declines that were similar in size to those experienced by New York, Maine, and Vermont. Comparable coefficients are roughly 1 percentage point smaller for the larger set of states in the triple-difference specification; they are of equal size in the difference-in-differences specifications.

\footnotetext{
${ }^{36} \mathrm{As}$ described in the note to the table, the regression specifications reported in Table 4 are from a specification similar to equation (9). The years in the sample are constrained by the availability of information on self-reported health status in the Current Population Survey. The specification is designed to trace out the differential evolution of the Medicaid coverage rates conditional on available economic and demographic covariates.
} 
Table 5: Coverage Changes in Regulated Markets: Private Coverage and the Fraction Uninsured

\begin{tabular}{|c|c|c|c|c|}
\hline & (1) & (2) & (3) & (4) \\
\hline Dependent Variable: Coverage Status & Private & Private & Uninsured & Uninsured \\
\hline \multirow{3}{*}{$\begin{array}{l}\text { Panel A: } \\
\text { Small Firm x Comm. Rating State x Post } \\
\text { Regulation }\end{array}$} & \multicolumn{4}{|c|}{ Effects of Adopting Regulations } \\
\hline & $-0.0941 * * *$ & $-0.0801 * * *$ & $0.0898^{* * *}$ & $0.0794 * * *$ \\
\hline & $(0.00718)$ & $(0.0124)$ & $(0.00910)$ & $(0.0155)$ \\
\hline Sample of States & Early Adopters & All Comp. & Early Adopters & All Comp. \\
\hline Estimation Framework & D-in-D-in-D & D-in-D-in-D & D-in-D-in-D & D-in-D-in-D \\
\hline Observations & 520,943 & 571,473 & 520,943 & 571,473 \\
\hline \multirow{3}{*}{$\begin{array}{l}\text { Panel B: } \\
\text { Small Firm x Comm. Rating State x Post } \\
\text { Regulation }\end{array}$} & \multicolumn{4}{|c|}{ Effects of Adopting Regulations } \\
\hline & $-0.109 * * *$ & $-0.103^{* * *}$ & $0.0841 * * *$ & $0.0959 * * *$ \\
\hline & $(0.0101)$ & $(0.0106)$ & $(0.026)$ & $(0.0163)$ \\
\hline Sample of States & Early Adopters & All Comp. & Early Adopters & All Comp. \\
\hline Estimation Framework & D-in-D & D-in-D & D-in-D & D-in-D \\
\hline Observations & 136,062 & 148,042 & 136,062 & 148,042 \\
\hline \multirow{3}{*}{$\begin{array}{l}\text { Panel C: } \\
\text { Small Firm x Comm. Rating State x Post } 1997\end{array}$} & \multicolumn{4}{|c|}{ Post-1997 Recoveries of Regulated Markets } \\
\hline & $0.0768^{* * *}$ & $0.0530^{* *}$ & $-0.0824^{* * *}$ & $-0.0487 * *$ \\
\hline & $(0.0120)$ & $(0.0209)$ & $(0.0101)$ & $(0.0223)$ \\
\hline Sample of States & Early Adopters & All Comp. & Early Adopters & All Comp. \\
\hline Estimation Framework & D-in-D-in-D & D-in-D-in-D & D-in-D-in-D & D-in-D-in-D \\
\hline Observations & 548,205 & 591,787 & 548,205 & 591,787 \\
\hline \multirow{3}{*}{$\begin{array}{l}\text { Panel D: } \\
\text { Small Firm x Comm. Rating State x Post } 1997\end{array}$} & \multicolumn{4}{|c|}{ Post-1997 Recoveries of Regulated Markets } \\
\hline & $0.0882^{* * *}$ & $0.0652^{* * *}$ & $-0.111^{* * *}$ & $-0.0694 * *$ \\
\hline & $(0.0171)$ & $(0.0224)$ & $(0.0120)$ & $(0.0280)$ \\
\hline Sample of States & Early Adopters & All Comp. & Early Adopters & All Comp. \\
\hline Estimation Framework & D-in-D & D-in-D & D-in-D & D-in-D \\
\hline Observations & 155,501 & 167,030 & 155,501 & 167,030 \\
\hline \multicolumn{5}{|c|}{$\begin{array}{l}\text { ***,**, and * indicate statistical significance at the .01, .05, and .10 levels respectively. Standard errors, reported beneath each } \\
\text { point estimate, allow for clusters at the state level. The samples in Panels A and B consist of individuals in households with at } \\
\text { least one child and one full-time employed adult from the March Current Population Survey in years 1987-1992 and 1996-1997. } \\
\text { The samples in Panels C and D consist of similarly situated households from 1996-1997 and 2003-2006. Each estimate comes } \\
\text { from a separate OLS regression. In Panels A and C, they are point estimates on a triple interaction between indicators for years } \\
\text { following the adoption of comprehensive regulations (Panel A) or years following substantial public insurance expansions (Panel } \\
\text { C), residence in a state that adopted comprehensive regulations, and absence of an adult working at a large firm. All } \\
\text { specifications control for state, year, and small-firm main effects as well as their two-way interactions. Additional controls } \\
\text { include a set of 2-digit occupation dummy variables, region dummy variables interacted with family income as a percent of the } \\
\text { poverty line, an indicator for having a single mother as the household's head, and an indicator for being black, additional } \\
\text { indicators for having two full time workers in the household and for the education levels of household adults, an indicator for } \\
\text { home ownership, and age group indicators. The estimates reported in Panels B and D contain the difference-in-difference } \\
\text { counterparts to the triple-difference specifications in Panels A and C. Estimates in columns } 2 \text { and } 4 \text { utilize the full sample of } \\
\text { states while estimates in columns } 1 \text { and } 3 \text { restrict the sample of treatment states to those that adopted their regulations in } 1993 \text {. }\end{array}$} \\
\hline
\end{tabular}


Table 6: Coverage Changes in Regulated Markets: Medicaid Coverage

Dependent Variable: Coverage Status

Panel A:

Small Firm x Comm. Rating State x Post

Regulation

Sample of States

Estimation Framework

Observations

Panel B:

Small Firm x Comm. Rating State x Post

Regulation

Sample of States

Estimation Framework

Observations

Panel C:

Small Firm x Comm. Rating State x Post 1997

Sample of States

Estimation Framework

Observations

Panel D:

Small Firm x Comm. Rating State x Post 1997

Sample of States

Estimation Framework
(1)

(2)

All Medicaid
(3)

Unhealthy Adult Medicid
(4)

Unhealthy Adult Medicid

\begin{tabular}{|c|c|c|}
\hline \multicolumn{3}{|c|}{ Medicaid Expansions Through 1997} \\
\hline $0.00915^{*}$ & 0.00600 & \\
\hline$(0.00489)$ & $(0.0103)$ & No Health Data Available in the \\
\hline Early Adopters & All Comp. & $\begin{array}{l}\text { March Demographic Supplements } \\
\text { of the Current Population Survey }\end{array}$ \\
\hline D-in-D-in-D & D-in-D-in-D & During the Pre-Regulation Period \\
\hline 520,943 & 571,473 & \\
\hline
\end{tabular}

Medicaid Expansions Through 1997

$0.00342 \quad-0.00144$

(0.00679) (0.0133)

Early Adopters All Comp.

D-in-D D-in-D

No Health Data Available in the

March Demographic Supplements

$136,062 \quad 148,042$

of the Current Population Survey

During the Pre-Regulation Period

Post-1997 Medicaid Expansions in Regulated Markets
0.000108
$-0.00661$
$0.0669 * * *$
0.0292
(0.00691)
(0.0112)
(0.00769)
(0.0313)
Early Adopters
All Comp.
Early Adopters
All Comp.
D-in-D-in-D
D-in-D-in-D
D-in-D-in-D
D-in-D-in-D
548,205
591,787
77,684
83,262

Post-1997 Medicaid Expansions in Regulated Markets

$\begin{array}{cccc}0.0265^{* *} & 0.00571 & 0.104^{* * *} & 0.0526 \\ (0.0120) & (0.0132) & (0.0174) & (0.0325) \\ \text { Early Adopters } & \text { All Comp. } & \text { Early Adopters } & \text { All Comp. } \\ \text { D-in-D } & \text { D-in-D } & \text { D-in-D } & \text { D-in-D } \\ 155,501 & 167,030 & 22,027 & 23,521\end{array}$

Observations

155,501

167,030

22,027

23,521

$* * *, * *$, and * indicate statistical significance at the $.01, .05$, and .10 levels respectively. Standard errors, reported beneath each point estimate, allow for clusters at the state level. The samples in Panels A and B consist of individuals in households with at least one child and one full-time employed adult from the March Current Population Survey in years 1987-1992 and 1996-1997. The samples in Panels C and D consist of similarly situated households from 1996-1997 and 2003-2006. Each estimate comes from a separate OLS regression. In Panels A and C, they are point estimates on a triple interaction between indicators for years following the adoption of comprehensive regulations (Panel A) or years following substantial public insurance expansions (Panel $\mathrm{C})$, residence in a state that adopted comprehensive regulations, and absence of an adult working at a large firm. All specifications control for state, year, and small-firm main effects as well as their two-way interactions. Additional controls include a set of 2-digit occupation dummy variables, region dummy variables interacted with family income as a percent of the poverty line, an indicator for having a single mother as the household's head, and an indicator for being black, additional indicators for having two full time workers in the household and for the education levels of household adults, an indicator for home ownership, and age group indicators. The estimates reported in Panels B and D contain the difference-in-difference counterparts to the triple-difference specifications in Panels A and C. Estimates in columns 2 and 4 utilize the full sample of states while estimates in columns 1 and 3 restrict the sample of treatment states to those that adopted their regulations in 1993. 
The results show that the full set of comprehensive regulation states differs from the set of early regulators in terms of the size of their subsequent coverage recoveries. The coefficients in Panels C and D are 2.3 to 4.2 percentage points smaller for the larger set of states, with the difference ranging from 25 to 40 percent of the coefficient for the early regulators. ${ }^{37}$ Table 6 presents equivalent sets of specifications documenting changes in Medicaid coverage, first for the full sample (Columns 1 and 2) and then for a sample restricted to unhealthy adults (Columns 3 and 4 ). The evidence shows that, after similar coverage expansions through 1997, the early- and late-regulating states diverged. Medicaid expansions in the late regulating states covered fewer unhealthy adults than Medicaid expansions in Maine, New York, and Vermont.

Taken together, the results have two implications. First, they confirm the results presented earlier showing that private coverage recoveries coincided with public insurance expansions in the first states to adopt comprehensive insurance-market regulations. Second, they show that similar recoveries did not occur in the comprehensive-regulation states that did not substantially expand their public coverage of unhealthy adults. The results reported in Appendix A.1 show that these findings are robust to a wide variety of criteria for selecting control groups. $3^{8}$

\subsection{Exploring the Potential Role of Public Insurance Expansions}

I conclude the analysis with estimates of equations (10) and (11). Since the primary explanatory variables of interest are new to these final specifications, I present the statelevel variation underlying the estimates in Table 7 and Figure 3.

\footnotetext{
37Since the early-regulating states are included in the larger set of states, the difference between the early and late regulators is substantially larger.

${ }^{38}$ Strategies explored in the appendix included matching on political characteristics (e.g., selecting the control group as other states that went for $\mathrm{Al}$ Gore in the 2000 presidential election) and matching on estimates of states' propensity to adopt comprehensive regulations using state-level economic and demographic characteristics.
} 


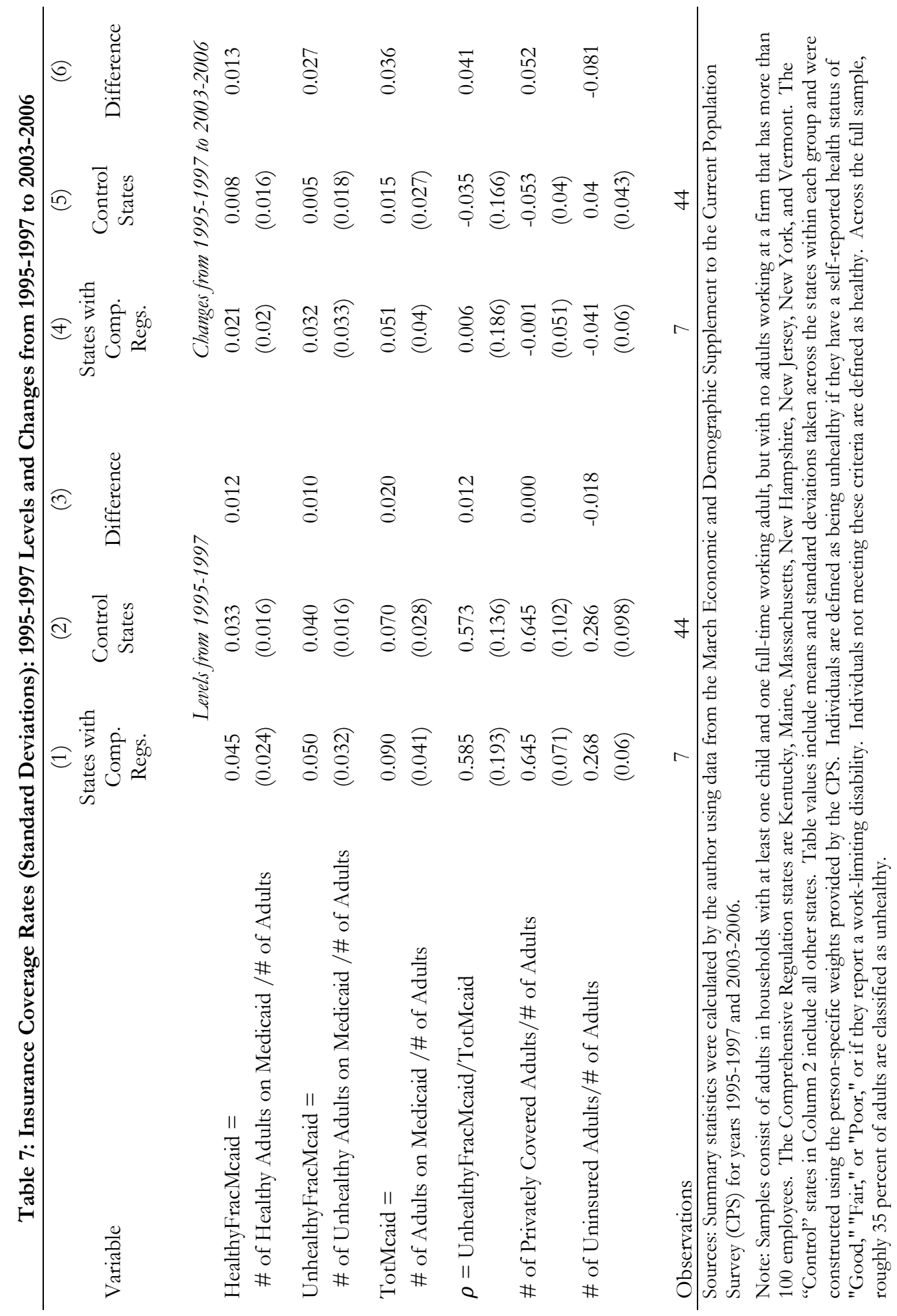


The means in Table 7 confirm the nature of the Medicaid expansions shown in Figure 2; comprehensively regulated states expanded their Medicaid programs to a greater degree than other states and their expansions disproportionately swept up unhealthy individuals. 39 The standard deviations of the changes in $\rho$ (defined as $\rho_{s, t}=$ $\frac{\text { UnhealthyFracMcaid }_{s, t}}{\text { TotFracMcaid }_{s, t}}$ ) and in Medicaid coverage of unhealthy adults highlight that, looking across states, there was substantial variation in both the size and composition of Medicaid expansions for adults. This is particularly true within the set of comprehensively regulated states. It is this variation within the set of comprehensively regulated states that is used to estimate the parameters of interest in equations (10) and (11).

Figure 3 provides a look at the state-level variation underlying the regression results in Table 8. The figure's four panels display partial correlations between private coverage rates and Medicaid coverage for two groups of adults (the healthy and the unhealthy) in two types of markets (those that are and are not governed by comprehensive regulations). To display the relationship between Medicaid's coverage of unhealthy adults and private coverage, for example, I regressed state level changes in Medicaid's coverage of unhealthy adults, as well as state level changes in private coverage rates, on changes in Medicaid's coverage of healthy adults. The figure displays the resulting residuals, with separate plots for states with different regulatory regimes. The partialing out of Medicaid's coverage of healthy adults leaves variation quite similar to that at work in the estimates of equation (10). The figure reveals a positive partial correlation between private coverage and Medicaid's coverage of unhealthy adults that is specific to the comprehensively regulated markets. Medicaid's coverage of healthy adults is negatively correlated with private coverage rates in both market types. In constructing these figures I have not yet made use of economic and demographic control variables to improve the

\footnotetext{
${ }^{39}$ In comparing Table 7 and Figure 2, it is important to note that I am now reporting Medicaid coverage of the healthy, for example, as a fraction of the total population rather than as a fraction of healthy adults.
} 


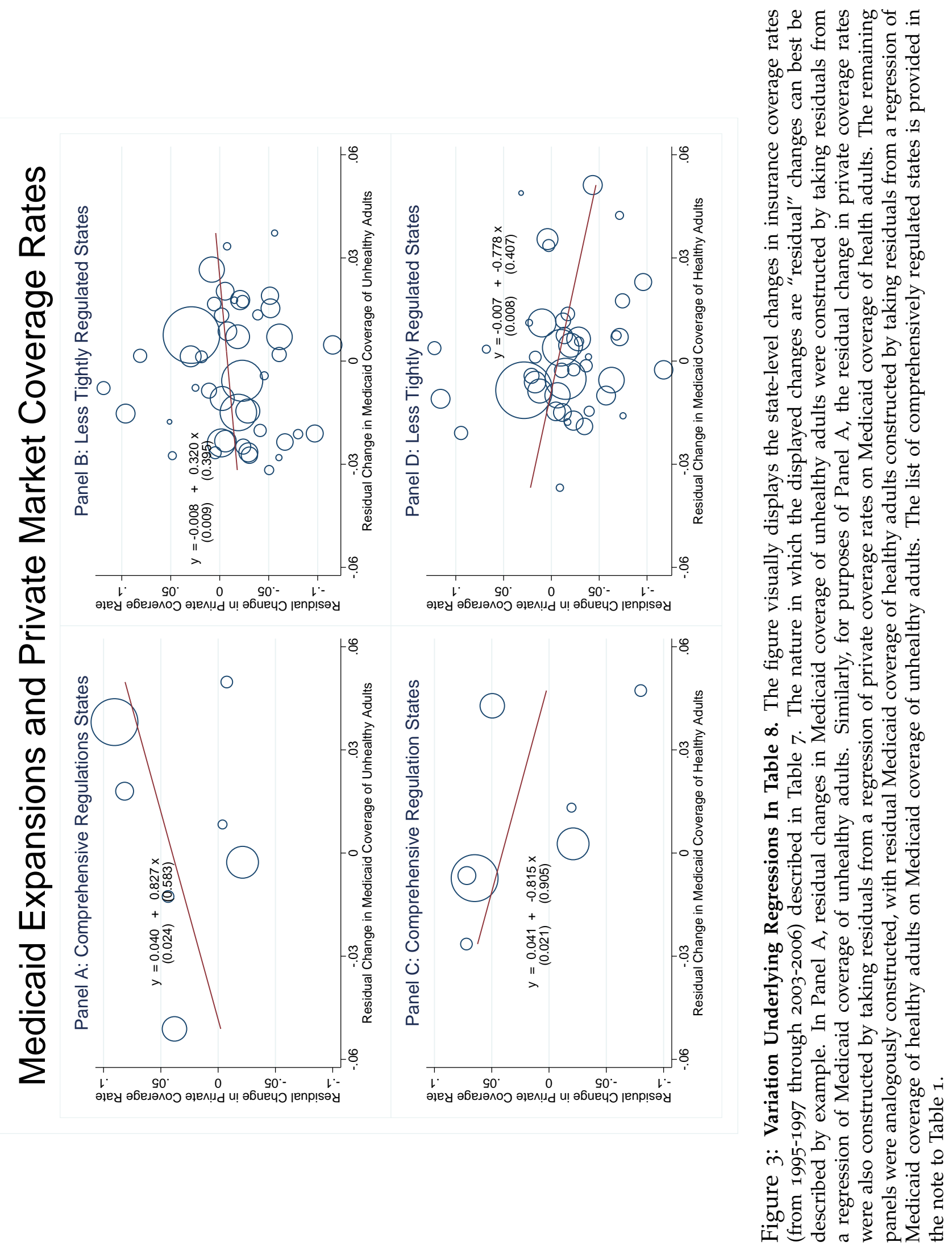


precision with which the relationships of interest are estimated. Collapsing the data into a single change for each state also reduces precision relative to the regression estimates in Table 8 by eliminating some of the variation associated with the rolling out of states' Medicaid expansions.

Table 8 presents the regression estimates. Consistent with Figure 3, the results show that expansions of public coverage for unhealthy adults have a significant, positive partial correlation with private coverage in markets operating under comprehensive regulations. The estimates in columns 1 and 2 show that a 7 percentage point expansion in public coverage of unhealthy adults, roughly the size of the expansions in Maine, New York, and Vermont, is associated with a 6 percentage point improvement in private coverage. Coverage of unhealthy adults has a weakly negative association with private coverage in less regulated markets. Coverage of healthy adults has a negative, statistically significant relationship with private coverage rates in both market types.

Columns 4 through 6 report estimates of equation (11), in which the explanatory variable of interest is $\rho_{s, t}=\frac{\text { UnhealthyFracMcaid }_{s, t}}{\text { TotFracMcaid }_{s, t}}$. Consistent with the incidence formulas derived in Section 1 , there is no partial correlation between $\rho_{s, t}$ and private coverage rates in markets that are not governed by comprehensive regulations (i.e., markets where $r=0$ ). Also consistent with the results from Section 1, there is a strong and positive partial correlation between $\rho_{s, t}$ and private coverage in the comprehensive-regulation states. Within this set of states, a two standard deviation increase in the change in $\rho_{s, t}$ from the mid-1990s through the mid-200os is associated with a 6 percentage point increase in private coverage rates. Controlling for the total fraction of the population receiving coverage through Medicaid does not materially affect this result. $4^{\circ}$

\footnotetext{
$4^{\circ} \mathrm{An}$ anonymous reviewer noted that the case for the public insurance mechanism could be strengthened by evidence that new unhealthy adult Medicaid beneficiaries have actually flowed from private to public insurance. Direct evidence of such flows is difficult to come by in the repeated cross-sections of the CPS. Nonetheless, several facts speak to the point. First, in the sample of households with incomes less than 300 percent of the federal poverty line (i.e., the sample for which Medicaid coverage was shown in
} 


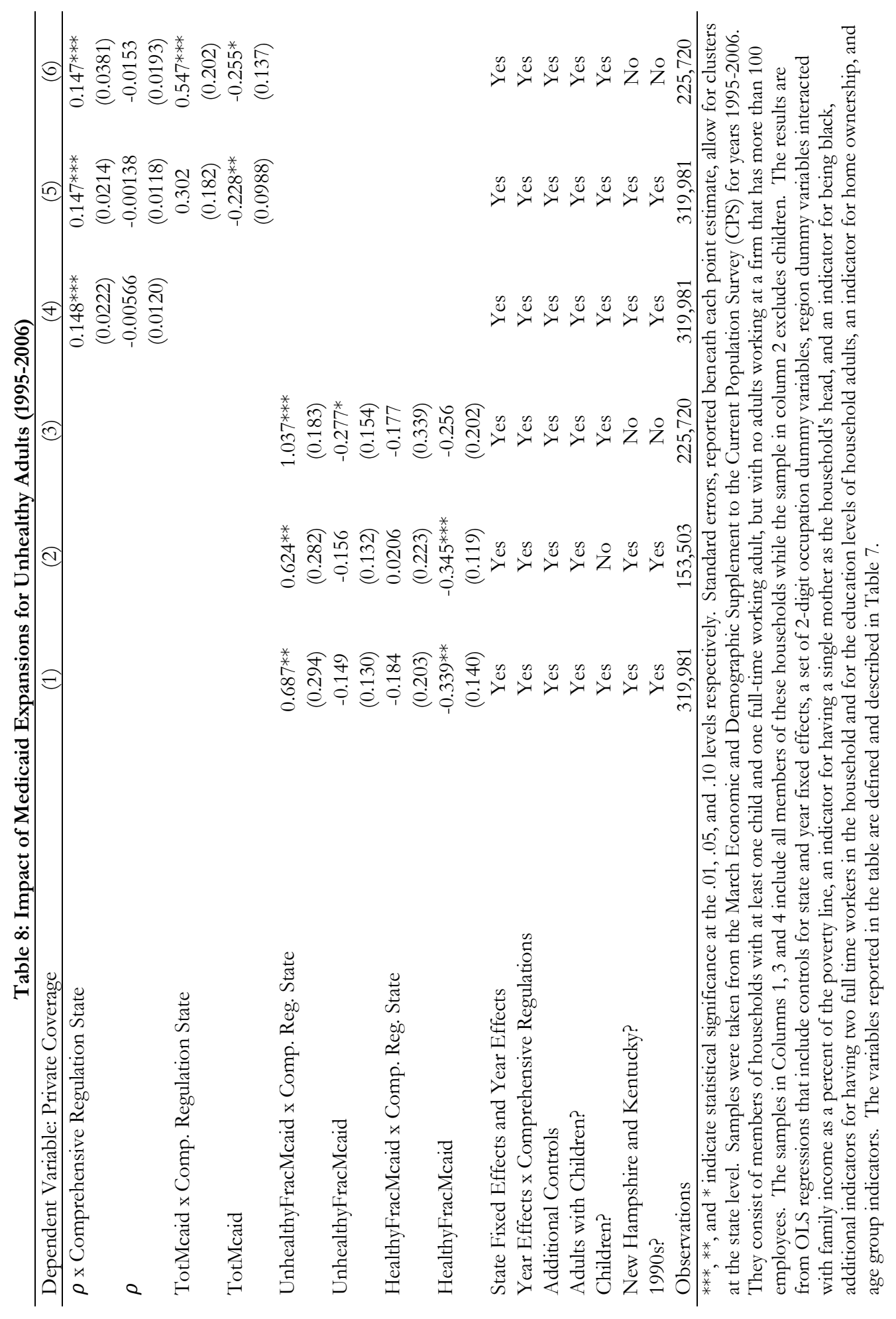


The results in columns 3 and 6 are worth additional discussion. In these specifications I restrict the sample to the years 2000 through 2006 and exclude the states that repealed their regulations before the end of the sample, namely Kentucky and New Hampshire. The estimates are thus produced using a sample of comprehensively regulated states that a) maintained their regulations for the duration of the sample, and b) had implemented their regulations at least 3 years prior to the beginning of the sample. One might worry that states like New Jersey and Massachusetts did not experience the same recoveries as Maine, New York, and Vermont because the initial effects of their regulations were still being realized during the late 1990s. The results show that the estimate of (11) is unaffected by these sample restrictions, while the primary result of interest in the estimate of (10) is strengthened.

\section{Discussion of Results}

The preceding analysis establishes a series of facts about the evolution of insurance coverage in markets governed by comprehensive regulations. During the mid-1990s, these markets experienced substantial declines in private coverage. These declines were followed by Medicaid expansions, which were particularly large and particularly targeted at unhealthy adults in Maine, New York, and Vermont. The Medicaid expansions were associated with significant declines in the fraction of individuals lacking insurance. Finally, the declines in the fraction uninsured were largest, and were aided by recoveries in private coverage rates, in the states that expanded Medicaid most aggressively

Panel F of Figure 2), more than 50 percent of individuals were covered by private insurance at some point during the year during the mid-200os. Among those adults who were covered by Medicaid (and in the presence of more generous SCHIP eligibility rules for children) more than 20 percent were in households in which at least one member was covered by private insurance. These households thus remain active in the private insurance market even following an adult's participation in Medicaid. One would expect their private market participation prior to an adult's Medicaid participation to have been much greater. Finally, just over 12 percent of the adults who were covered by Medicaid reported having themselves been covered by private insurance at some point during the year. 
for relatively unhealthy adults. These facts are consistent with important roles for the incidence implications of regulatory regimes, as characterized in Section 1.

The results do not show, of course, that community rating regulations caused New York, Maine, and Vermont to expand their Medicaid programs as aggressively as they did. While community rating creates political economy forces that work in that direction, these states may independently have had a stronger taste for Medicaid expansions than other states. The effect of community rating on the incidence of public insurance expansions appears important, however, for explaining the recoveries of private coverage in the comprehensively regulated markets. The incidence mechanism can explain both the reversal of the usual "crowding out" result and the particular pattern of recoveries within the set of comprehensively regulated states.

As further support for the importance of community rating's impact on the incidence of public insurance programs, I provide two additional pieces of analysis. Appendix 2 presents a calibration, conducted using data from the Medical Expenditure Panel Survey (MEPS), of the potential effect of these public insurance expansions on premiums in the comprehensively regulated markets. The calibration shows that the post-1993 public insurance expansions had the potential to hold community-rated premiums down by around $\$ 1,700$ for a family of 4 , with most of this impact coming from coverage of unhealthy adults. To convert this premium impact into an estimated change in private insurance coverage, one need only express it as a percent of the relevant premiums and multiply by the price elasticity of insurance take-up in the relevant markets. Bernard and Banthin (2008) estimate that, in 2002, the average non-group premium for families was around $\$ 4,400$ while the average small group premium was on the order of $\$ 8,500$. $\$ 1,700$ amounts to roughly 25 percent of the average family premium in the non- and small-group markets. Chernew, Cutler, and Keenan (2005) estimate that the elasticity of insurance take-up with respect to premiums is approximately -0.1, while Marquis 
and Long (1995) estimate an elasticity of -0.4. Elasticities inferred from survey data by Krueger and Kuziemko (2011), who discuss a variety of potential biases in the earlier empirical work, are much closer to -1. With an elasticity on the order of -0.4, the public insurance expansions could explain increases in private coverage of roughly 7 percentage points on a baseline coverage rate of around 70 percent.

Finally, I investigate the potential roll of an alternative explanation for recoveries of private coverage in comprehensively regulated markets. Past work has found evidence that HMOs (Buchmueller and DiNardo, 2002; Buchmueller and Liu, 2005; LoSasso and Lurie, 2009) and high deductible health plans (Hall, 2000; Wachenheim and Leida, 2007) expanded their market shares in comprehensively regulated markets during the mid 1990s. These changes have the potential to enable low cost types to separate from high cost types, potentially resulting in a rebound of coverage rates (Rothschild and Stiglitz, 1976). I use MEPS data to investigate the importance of these phenomena over the period during which the recoveries occurred. MEPS data show that, among the privately insured, the share of total health expenditures that were paid for by insurance actually rose in the Northeast census region from 1996 to 2004. This increase was just as large as increases in other census regions. Similarly, the total health expenditures of those with private insurance rose by indistinguishably different amounts in the Northeast and other census regions during this time period. ${ }^{41}$ There is thus no clear evidence for a differential decline in plan generosity from 1996 to $2004 \cdot{ }^{42}$

This analysis does not imply that the rise of HMOs and high-deductible health plans had no effect on coverage rates in these markets. Prior work documented a differential expansion of these plans in the regulated markets prior to 1996. The logic of revealed

\footnotetext{
${ }^{41}$ These points hold both when examining all insured individuals and when restricting the sample to those who would not have had access to large-group insurance.

${ }^{42}$ The MEPS was not collected prior to 1996. Consequently, it cannot be used to determine the extent to which pre-1996 shifts towards HMOs and high-deductible plans resulted in differential changes in these metrics.
} 
preference suggests that, had these options been unavailable, the initial coverage declines would have exceeded those that were ultimately observed. The observed recovery of these markets should be viewed as a lower bound on the recovery relative to a counterfactual in which no adjustments in plan offerings and public insurance took place. To attribute a 7 percentage point recovery to the effects of public insurance expansions, one need not believe that the rise of HMOs and high-deductible plans had no effect.

\section{Conclusion}

This paper studies the relationship between two instruments of health-based redistribution: tax-financed public insurance and regulations that generate within-market transfers from the healthy to the sick by equalizing their premiums. The economic incidence of these policies is tightly intertwined. Premium regulations risk substantial adverse selection when insurance purchases are voluntary and when large numbers of unhealthy individuals remain on the private market. If these regulations have induced adverse selection, the incidence of Medicaid expansions, in particular when targeted at the unhealthy, can become favorable for broad segments of the population. This is particularly true when the costs of states' Medicaid programs are only partially borne by local populations.

The 2010 Patient Protection and Affordable Care Act (PPACA) contains regulatory measures including community rating rules, guaranteed issue requirements, and an individual mandate to purchase insurance. Three of PPACA's features are designed to go farther than previous regulations to ensure that pooling of the healthy and sick occurs. ${ }^{43}$ First, by mandating insurance purchases, PPACA prevents healthy individuals

\footnotetext{
43See Kaiser (2010) for a detailed summary of the health bill's provisions.
} 
from avoiding the costs of the sick by exiting the insurance market. ${ }^{44}$ Second, the PPACA contains provisions that limit adjustment along the intensive margin of insurance generosity. It does so by expanding minimum coverage requirements, tightening limits on out-of-pocket spending, and instituting maximum deductibles. Third, the PPACA's guaranteed issue requirements are more stringent than those typically in place across the states.

These regulatory measures will create substantial pressure in favor of shedding the cost of unhealthy individuals onto federal taxpayers. Indeed, the law would generously compensate such efforts, as the federal government will finance more than 90 percent of the cost of its associated Medicaid expansions. 45 Whether states will target future Medicaid expansions towards the unhealthy, as in Maine, New York, and Vermont, remains to be seen. This paper thus highlights a unique set of issues that will be ripe for study during PPACA's implementation.

On a more general level, this paper points to a need for analysis of the interplay between redistributive regulations and tax-financed transfer programs in settings where these policies coexist. In an early discussion of the incidence and political economy of mandated employee benefits (a particular form of regulatory redistribution), Summers (1989) offered the possibility of regulatory redistribution as a political compromise between limited social insurance (a common preference on the right) and expansions in on-budget, tax-financed social insurance (a common preference on the left). While that

\footnotetext{
44The introduction of the mandate has two distinct incidence implications. First, as intended, it acts to prevent the erosion of insurance value by preventing extensive-margin adverse selection. The second point is more subtle, and requires keeping in mind that "premium incidence," as derived in Section 1, only directly affects the pool of insurance purchasers (it has no effect on non-purchasers until the point at which it brings them into the pool). By forcing all individuals to participate in the pool, the mandate expands the fraction of the population to which premium incidence applies. Consequently the mandate may, somewhat surprisingly, increase the political economy pressures in favor of shedding the costs of unhealthy individuals onto federal taxpayers.

45The federal government's use of these levers provides a prominent example of the state-federal interactions driving the rise of state spending on redistributive programs over the last half century (Baicker, Clemens, and Singhal, Forthcoming).
} 
political compromise recently appears to have reached its limit, the intervening decades generated significant expansions in redistribution of this form. Further investigation of the effects of such policies should be a priority. 


\section{References}

Baicker, K., J. Clemens, and M. Singhal (Forthcoming): “The Rise of the States: US Fiscal Decentralization in the Postwar Period," Journal of Public Economics.

Bernard, D., AND J. Banthin (2008): "Premiums in the Individual Health Insurance Market for Policyholders under Age 65: 2002 and 2005," Discussion Paper 202, Agency for Healthcare Research and Quality, Rockville, MD.

BorJas, G. (1999): "Immigration and welfare magnets," Journal of labor economics, 17(4), 607.

Buchmueller, T., and J. DiNardo (2002): “Did community rating induce an adverse selection death spiral? Evidence from New York, Pennsylvania, and Connecticut," American Economic Review, 92(1), 280-294.

Buchmueller, T. C., AND S. LIU (2005): “Health insurance reform and HMO penetration in the small group market," Inquiry, 42(4).

Chernew, M., D. M. Cutler, And P. S. Keenan (2005): “Increasing health insurance costs and the decline in insurance coverage," Health Services Research, 40(4), 1021-1039.

Cogan, J., R. Hubbard, and D. Kessler (2010): “The effect of Medicare coverage for the disabled on the market for private insurance," Journal of health economics, 29(3), $418-425$.

Crocker, K., and A. Snow (1986): “The efficiency effects of categorical discrimination in the insurance industry," The Journal of Political Economy, 94(2), 321-344.

Crowley, J. (2003): “Medicaid Medically Needy Programs: An Important Source of Medicaid Coverage," Discussion Paper 4096, Kaiser Foundation, Washington, DC. 
Cutler, D. M., ANd J. Gruber (1996): “Does public insurance crowd out private insurance," Quarterly Journal of Economics, 111(2), 391-430.

Cutler, D. M., and S. J. Reber (1998): "Paying for Health Insurance: The Trade-Off between Competition and Adverse Selection*," Quarterly Journal of Economics, 113(2), $433-466$.

Davidoff, A., L. Blumberg, and L. Nichols (2005): "State health insurance market reforms and access to insurance for high-risk employees," Journal of Health Economics, 24(4), 725-750.

Downs, A. (1957): "An economic theory of political action in a democracy," The Journal of Political Economy, 65(2), 135-150.

Einav, L., A. Finkelstein, and P. Schrimpf (2007): “The welfare cost of asymmetric information: Evidence from the UK annuity market," NBER Working Paper 13228.

Feldstein, M., and M. Wrobel (1998): “Can state taxes redistribute income?," Journal of Public Economics, 68(3), 369-396.

Finkelstein, A., J. Poterba, and C. Rothschild (2009): “Redistribution by insurance market regulation: Analyzing a ban on gender-based retirement annuities," Journal of financial economics, 91(1), 38-58.

GAO (2003): “Federal and State Requirements Affecting Coverage Offered by Small Businesses," Discussion Paper GAO-03-1133, Government Accountability Office.

Glaeser, E. L., AND J. Scheinkman (1998): “Neither a borrower nor a lender be: An economic analysis of interest restrictions and usury laws," Journal of Law and Economics, $41(1), 1-36$. 
Gruber, J., and K. Simon (2008): “Crowd-out 10 years later: Have recent public insurance expansions crowded out private health insurance?," Journal of Health Economics, $27(2), 201-217$.

Hall, M. (2000): “An Evaluation of New York's Reform Law," Journal of Health Politics, Policy and Law, 25(1), 71 .

Herring, B., and M. Pauly (2006): “The Effect of State Community Rating Regulations on Premiums and Coverage in the Individual Health Insurance Market," NBER Working Paper 12504.

Herz, E., C. Peterson, and E. Baumrucker (2008): “State Childrens Health Insurance Program (SCHIP): A Brief Overview," State Children's Health Insurance Program (SCHIP), p. 99.

KaISER (2010): "Summary of New Health Reform Law," Discussion Paper 8061, The Henry J. Kaiser Family Foundation, Menlo Park, CA.

Krueger, A., And I. Kuziemko (2011): “The demand for health insurance among uninsured Americans: Results of a survey experiment and implications for policy," Discussion paper, National Bureau of Economic Research.

LeE, D., AND E. SAEZ (2008): “Optimal minimum wage policy in competitive labor markets," Discussion paper, National Bureau of Economic Research.

LiNDBECK, A. (1985): "Redistribution policy and the expansion of the public sector," Journal of Public Economics, 28(3), 309-328.

LoSAsso, A. T., AND I. Z. LuRIE (2009): “Community rating and the market for private non-group health insurance," Journal of Public Economics, 93(1-2), 264-279. 
MARquis, M. S., AND S. H. LoNG (1995): “Worker demand for health insurance in the non-group market," Journal of Health Economics, 14(1), 47-63.

Monheit, A., AND B. SChONE (2004): “How has small group market reform affected employee health insurance coverage?," Journal of Public Economics, 88(1-2), 237-254.

OAtes, W. (1999): “An essay on fiscal federalism," Journal of economic literature, 37(3), 1120-1149.

Peterson, P., And M. Rom (1990): Welfare magnets: A new case for a national standard. Brookings Institution Press.

Posner, R. (1971): “Taxation by regulation," The Bell Journal of Economics and Management Science, 2(1), 22-50.

Rothschild, C. (2007): “The efficiency of categorical discrimination in insurance markets," Journal of Risk and Insurance.

Rothschild, M., AND J. StigLitz (1976): “Equilibrium in competitive insurance markets: An essay on the economics of imperfect information," Quarterly Journal of Economics, 90(4), 629-649.

SIMON, K. (2005): "Adverse selection in health insurance markets? Evidence from state small-group health insurance reforms," Journal of Public Economics, 89(9-10), 1865-1877.

SloAn, F. A., ANd C. J. Conover (1998): "Effects of state reforms on health insurance coverage of adults," Inquiry, 35(3), 280-293.

Summers, L. (1989): "Some simple economics of mandated benefits," The American Economic Review, 79(2), 177-183.

Tiebout, C. (1956): "A pure theory of local expenditures," The journal of political economy, 64(5), 416-424. 
WACHENHEIM, L., AND H. LeIDA (2007): “The impact of guaranteed issue and community rating reforms on individual insurance markets," .

Zuckerman, S., J. McFeeters, P. Cunningham, and L. Nichols (2004): “Trends: Changes In Medicaid Physician Fees, 1998-2003: Implications For Physician Participation," Health Affairs.

ZuCKERMAN, S., AND S. RAJAN (1999): "An alternative approach to measuring the effects of insurance market reforms," Inquiry, 36(1), 44-56. 


\section{Appendix (For Online Publication)}

\section{A.1: Robustness Analysis}

Tables A1 and A2 explore the robustness of the results in Table 5 to changes in the sample of control states and in the sample of treatment states. Table Ai focuses on the initial effect of implementing regulations (following Panels A and B from Table 5) while Table A2 focuses on the recovery of regulated markets following the implementation of SCHIP (following Panels C and D from Table 5). Both tables report a combination of triple- and double-difference estimates. The estimates take the same form as the estimates of equation (9) and its difference-in-differences counterpart.

The first rows of Table A1 and A2 demonstrate robustness to restricting the sample of states used as controls. Restricting the control group to the non-regulated states that voted for $\mathrm{Al}$ Gore in the 2000 Presidential election has little impact on the results. The same can be said for 4 samples selected using estimates of each state's propensity to adopt comprehensive regulations, with point estimates averaging roughly -8.5 percentage points across these specifications. Propensity score 1 was estimated on the basis of state-level economic and demographic characteristics and an indicator for whether or not the state voted for Al Gore. Propensity score 2 is based solely on state-level economic and demographic characteristics. Propensity scores 3 and 4 are equivalent to 1 and 2, but are based on the economic and demographic characteristics of households on the non- and small-group insurance markets (as opposed to the entire state population). Across these specifications, the double-difference methodology yields larger estimates (averaging -10 percentage points) than the triple-difference methodology in all cases. Estimates of the post-1997 recoveries range from 7 percentage points to just over 9 percentage points.

The next rows of Tables A1 and A2 investigate the results' sensitivity to excluding any one of the treated states from the sample. New York emerges as an important driver 


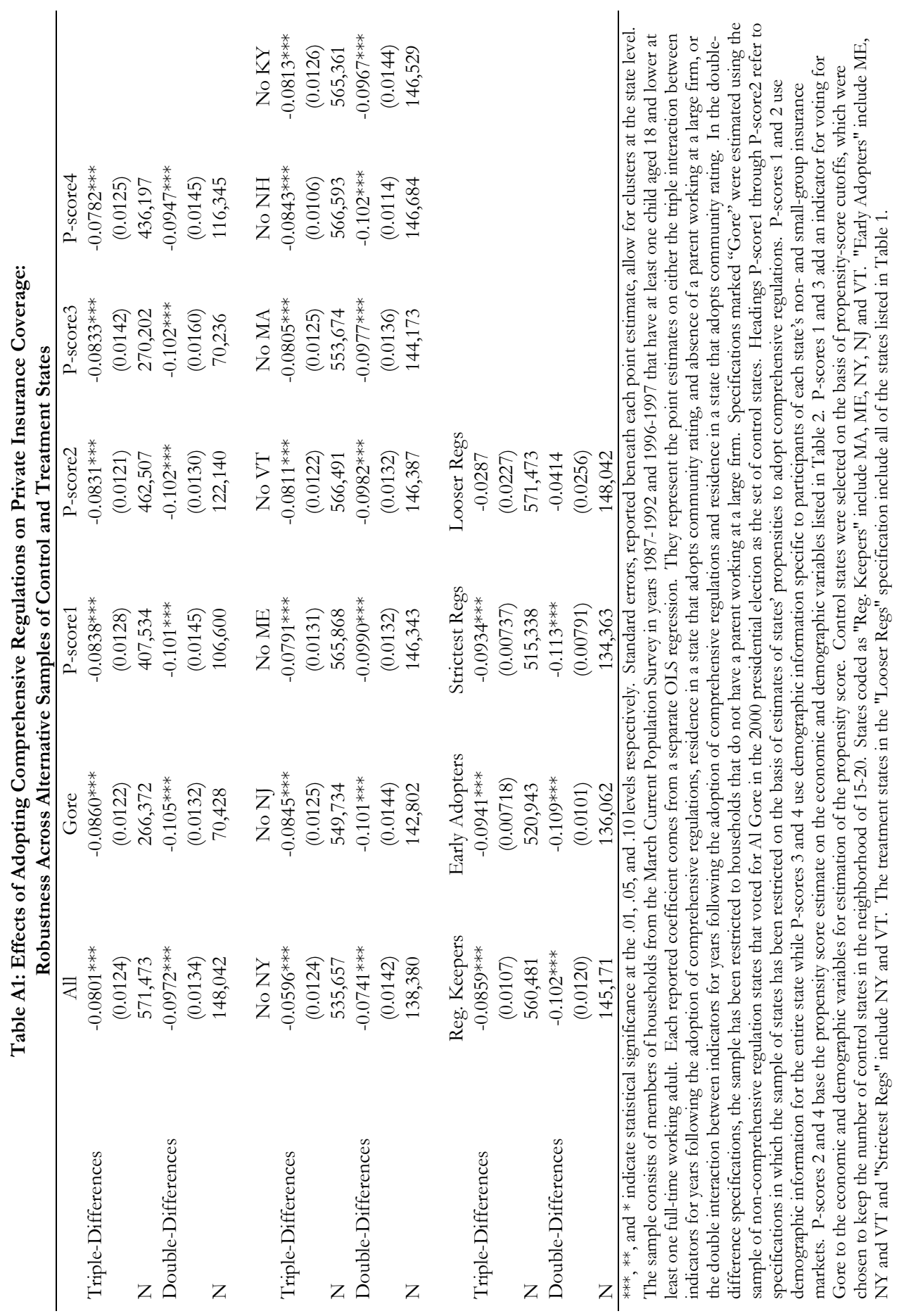




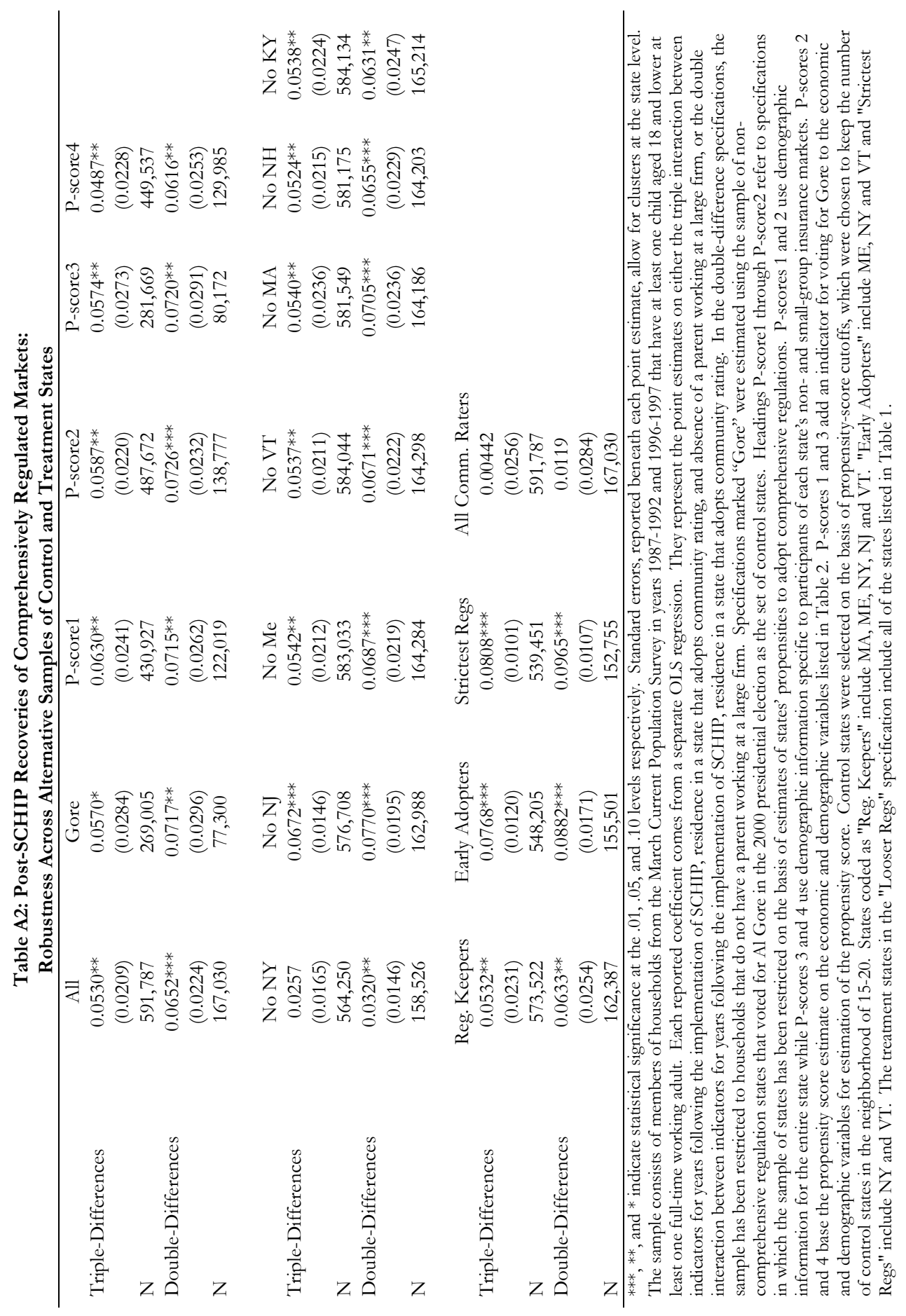


of the magnitudes of the results in both tables. Estimates of both the initial coverage declines and later coverage recoveries decline by 2-3 percentage points when New York is excluded from the sample. New Jersey pushes the estimated size of the recovery down by roughly I percentage points. The New York and New Jersey outcomes are important drivers of the results presented in Table 8, as New York was the most aggressive of the comprehensive regulation states in its expansion of Medicaid for unhealthy adults, while New Jersey was the least.

The final rows of Tables A1 and A2 explore differences in the effects of regulations across groups of states that may objectively be expected to have different experiences. The first column excludes states that abandoned their regulations during the sample (i.e., New Hampshire and Kentucky). As a check on the plausibility of the public insurance mechanism, it is essential that these states do not drive the results, and indeed they do not. The second column restricts the treatment group to states that adopted regulations in 1993 (namely Maine, Vermont, and New York). Estimated effects are modestly larger when focusing on these states, as would be expected. Similar results are obtained when restricting the treatment group to New York and Vermont, which were the only states to implement pure (as opposed to modified) community rating laws in both their non- and small-group markets.

Finally, I consider the effect of adding less-strictly regulated states to the treatment group. Specifically, I define the treatment group to include all states described in Table 1; this includes 6 additional states which either had weak guaranteed issue requirements or which enforced community rating in their small-group markets, but not in their nongroup markets. The addition of these less-comprehensively regulated states significantly reduces the estimated effects of regulations. In all cases the estimates become statistically insignificant, suggesting that comprehensive regulations cause much more significant coverage disruptions than relatively modest regulations. 
These last results suggest that regulating both of the markets to which households have access has much greater effects than regulating one of them. It is also relevant that 4 of the 6 less tightly regulated states utilized high risk pools during the 1990s. High risk pools provide subsidized coverage for high cost types who would otherwise put upward pressure on community-rated premiums. None of the comprehensively regulated states made use of such pools as means to limit adverse selection pressures during the sampleperiod.

\section{A.2: Calibration of the Potential Effect of Public Insurance Expansions on Premiums in Regulated Markets}

The potential effect of public insurance expansions on community-rated premiums can be approximated using the observed expenditures and health status of those who are newly eligible for, and participating in, public insurance. $4^{46}$ Table A3 calibrates the effect of all post-1993 public insurance expansions on the community-rated premium of a family with 2 adults and 2 children. From 1993 to 2004, the number of Medicaid (or SCHIP) beneficiaries expanded by around to million children, 5 million non-disabled adults, and 3 million disabled persons. States with comprehensive regulations accounted

\footnotetext{
${ }^{46}$ Two important caveats arise in this context. Health spending will reflect the reimbursement rates offered to providers by public programs, which are typically lower than those offered by private insurers. The calibration accounts for this using an estimate from Zuckerman, McFeeters, Cunningham, and Nichols (2004) that Medicaid reimbursement rates are roughly 30 percent lower than reimbursement rates that prevail under Medicare (for comparable services). It will also reflect difficulties in obtaining care due to physician (un)willingness to see Medicaid patients. Pregnant women and the disabled were explicitly covered by Medicaid on account of their high health expenditures. The Medical Expenditure Panel Survey (MEPS) confirms that (non-disabled) adults on public insurance have higher health expenditures than the typical adult on private coverage. (It may still be the case, of course, that observed differences understate real differences in what the publicly insured would spend if they were on private insurance.) Children, however, were not made eligible on account of their health. MEPS data suggest that children of any health status spend less on health care when publicly insured than when privately insured. I thus compare publicly and privately insured children on the basis of their health status rather than their observed expenditures.
} 
for roughly 1 million of these children, 1.1 million non-disabled adults, and 500,000 disabled persons while accounting for roughly 11 percent of the nation's population. The vast majority of the expanded coverage of unhealthy adults and the disabled (roughly four fifths) drew from the pool of non- and small-group market participants. 47

I examine the expenditures of newly eligible individuals using health spending data from the 2004 Medical Expenditure Panel Survey (MEPS). To proxy for newly-eligible status, I use household employment information. Specifically, I focus attention on those who are in households with at least one full-time employed adult. The vast majority of those eligible for Medicaid prior to the 1990s expansions were in households in which there were no full-time employed adults. These expansions were designed to target the working poor, i.e., low income households in which at least one family member works regularly. In this sample, the typical non-disabled, publicly insured adult spends roughly $\$ 1,325$ (standard error of $\$ 611$ ) more per year than the typical privately insured adult. The typical publicly insured disabled individual spends roughly $\$ 8,000$ (standard error of \$671) more than the typical adult. Finally, I estimate that, if privately insured, newly eligible children would have spent roughly $\$ 100$ more than the typical privately insured child.

The potential premium impacts of expanded coverage for adults and the disabled are much larger than that associated with children. There were approximately 5 million adults with private insurance in the non- and small-group markets of the comprehensively regulated states in 2004. I assume that four-fifths, or 880 thousand, of the newly covered, non-disabled adults came from the non- and small-group markets. ${ }^{8}$

\footnotetext{
47This result does not stem directly from evidence presented earlier in the paper, but can be seen quite readily in the data when comparing Medicaid coverage of unhealthy adults with and without access to insurance through the large group market.

${ }^{48}$ This assumption is driven by CPS data suggesting that roughly one-fifth of new beneficiaries came from families whose alternative source of insurance would have come through the large group insurance market.
} 


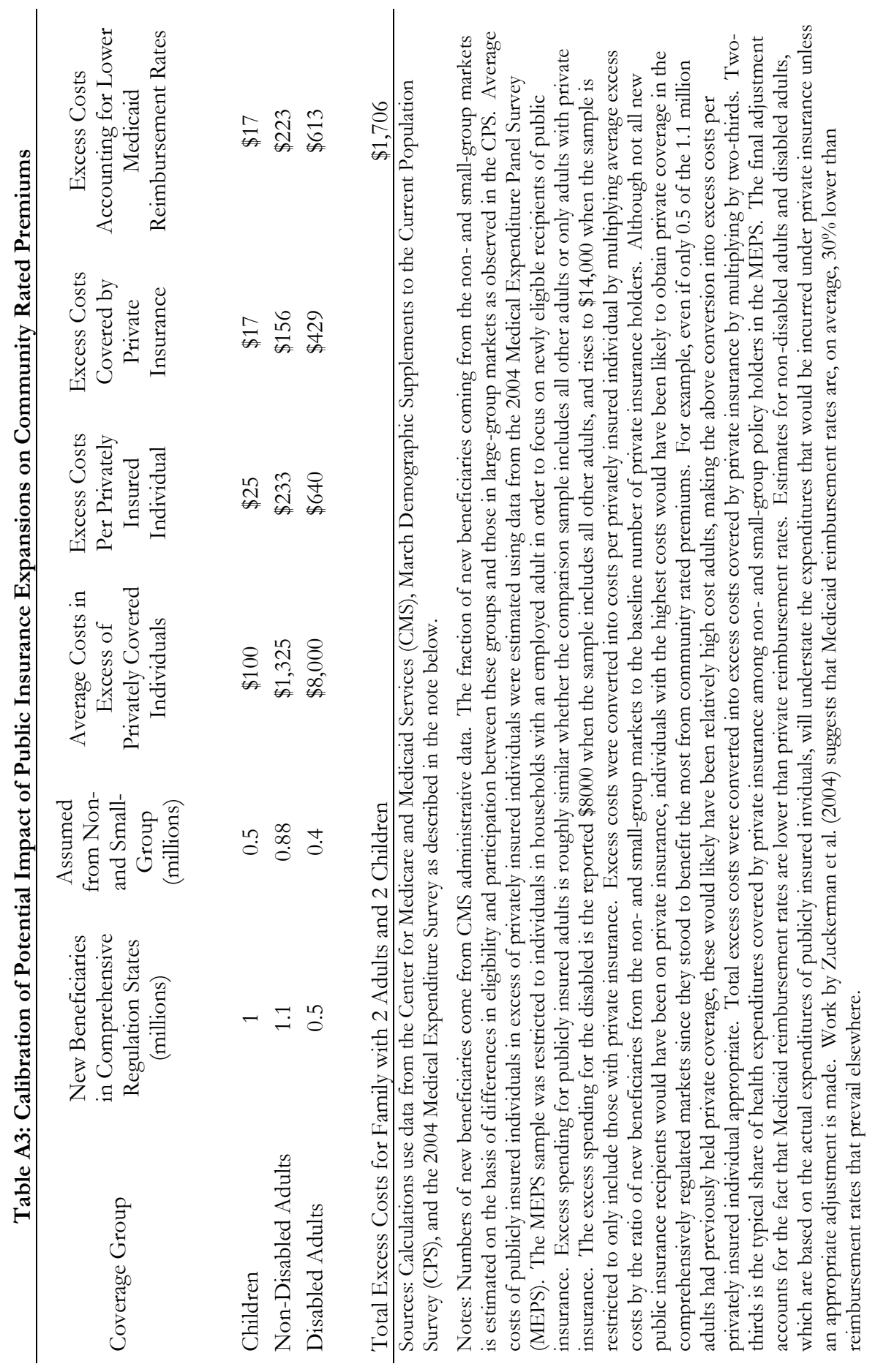


Their excess spending of $\$ 1,325$ per person thus amounts to roughly $\$ 233$ per adult still on these markets. The excess spending of the newly-covered disabled population amounts to $\$ 640$ per adult on these markets. ${ }^{49}$ If two-thirds of these expenditures would have been covered by private insurance (a typical share for the privately insured on the non- and small-group markets), the premium impact would amount to nearly $\$ 585$ per adult. A final adjustment, to account for Medicaid's relatively low reimbursement rates (which will depress observed spending by those on public insurance relative to what they would spend were they on private insurance), raises this estimate to $\$ 836$ (see Zuckerman, McFeeters, Cunningham, and Nichols (2004))..$^{50}$ Similar calculations for expanded children's coverage yields an estimate of roughly \$17 per child. The post-1993 public insurance expansions may thus have held down community-rated premiums by around $\$ 1,700$ for a family of 4 .

\footnotetext{
${ }^{49}$ Note that while many new Medicaid participants would previously have been uninsured, those with particularly high health expenditures would likely have acquired private insurance in the comprehensively regulated markets. These are precisely the individuals with the most to gain from purchasing communityrated insurance. Furthermore, insuring high cost uninsured individuals can reduce the severity of adverse selection in the same way as insuring high cost individuals with private insurance; the presence of high cost individuals in the pool of the insured can preclude the realization of pooling equilibria. Because of this, actual declines in premiums will tend to understate the extent to which public insurance expansions reduce adverse selection pressures.

${ }^{50}$ This is, if anything, an understatement. Zuckerman, McFeeters, Cunningham, and Nichols (2004) compare Medicaid reimbursement rates to Medicare reimbursement rates. Private reimbursements regularly exceed Medicare's reimbursements by an additional 33-50 percent.
} 